Advanced Combustion Diagnostics and Control for Furnaces, Fired Heaters and Boilers

\title{
Advanced Combustion Diagnostics and Control for Furnaces, Fired Heaters and Boilers Final Report
}

\author{
Project Title: $\quad$ Advanced Combustion Diagnostics and Control for Furnaces, Fired Heaters and \\ Boilers
}

Covering Period: September 29, 2006 through December 29, 2009

Date of Report: $\quad$ March 30, 2010

Recipient: $\quad$ The Dow Chemical Company

2301 Brazosport Blvd., B-1216. Freeport, TX. 77541-3257

$\begin{array}{ll}\text { Award Number: } & \text { DE-FG36-06GO16093 } \\ \text { Subcontractors: } & \text { Analytical Specialties } \\ & 910 \text { Gemini, Houston, TX } 77058 \\ & 281-488-0409\end{array}$

Principle Investigator: Dr. JD Tate, 979-238-4268, jdtate@dow.com

Project Team: $\quad$ Dow: Linh D.Le, Brant Shields, Gerald Frederick, Duncan Coffey, Eduardo Arrieta, Jeff Owens, Leo Chiang, Serena Stephenson, Rod Spitler

Yokogawa: Trevor Knittel, Jie Zhu, Alan Cowie

\section{Executive Summary:}

The objective of this project was to develop and apply enabling tools and methods towards advanced combustion diagnostics and control of fired-equipment in large-scale petrochemical manufacturing. There are a number of technology gaps and opportunities for combustion optimization, including technologies involving advanced in-situ measurements, modeling, and thermal imaging. These technologies intersect most of manufacturing and energy systems within the chemical industry. This project leveraged the success of a previous DOE funded project led by Dow, where we co-developed an in-situ tunable diode laser (TDL) analyzer platform (with Analytical Specialties Inc, now owned by Yokogawa Electric Corp.). The TDL platform has been tested and proven in a number of combustion processes within Dow and outside of Dow.

The primary focus of this project was on combustion diagnostics and control applied towards furnaces, fired heaters and boilers. Special emphasis was placed on the development and application of in-situ measurements for $\mathrm{O}_{2}, \mathrm{CO}$ and methane since these combustion gases are key variables in optimizing and controlling combustion processes safely. Current best practice in the industry relies on measurements that suffer from serious performance gaps such as limited sampling volume (point measurements), poor precision and accuracy, and poor reliability. Phase I of the project addressed these gaps by adding improved measurement capabilities such as $\mathrm{CO}$ and methane (ppm analysis at combustion zone temperatures) as well as improved optics to maintain alignment over path lengths up to 30 meters. Proof-of-concept was demonstrated on a modern olefins furnace located at Dow Chemical's facility in Freeport TX where the improved measurements were compared side-by-side to accepted best practice techniques (zirconium oxide and catalytic bead or thick film sensors).

After developing and installing the improved combustion measurements $\left(\mathrm{O}_{2}, \mathrm{CO}\right.$, and methane), we also demonstrated the ability to improve control of an olefins furnace (via CO-trim) that resulted in significant energy savings and lower emissions such as NOx and other greenhouse gases. The cost to retrofit measurements on an existing olefins furnace was found to be very attractive, with an estimated payback achieved in 4 months or less. 
Table of Content

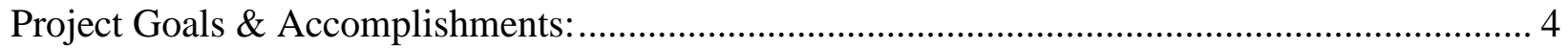

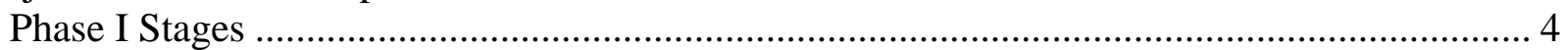

Phase II Stages ...................................................................................................... 4

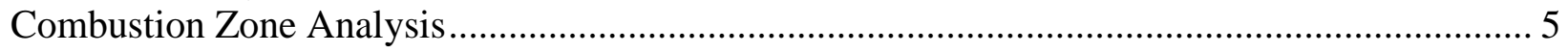

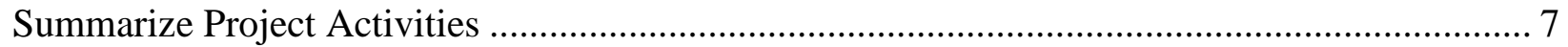

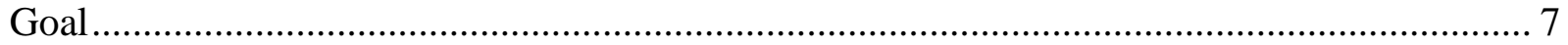

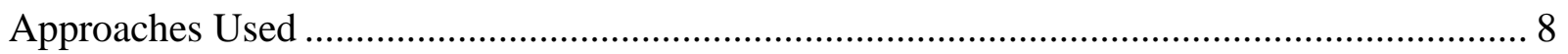

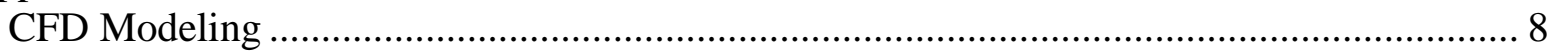

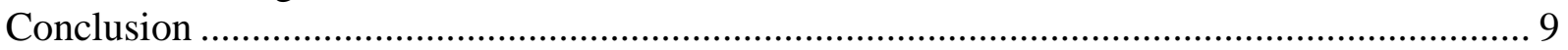

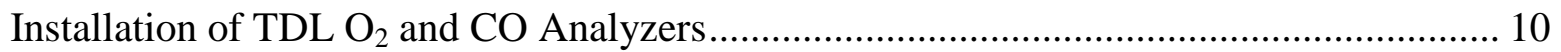

Conclusions From Installation of TDL $\mathrm{O}_{2}$ and $\mathrm{CO}$ Analyzers ........................................ 12

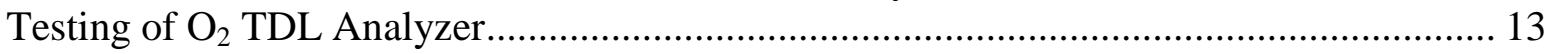

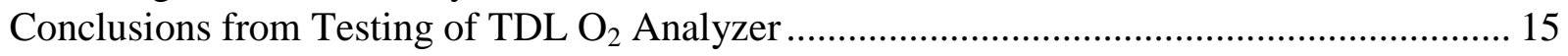

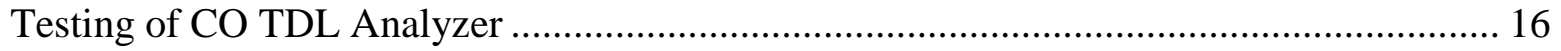

Condition $1 \& 2$ - Normal and Abnormal Operations.................................................. 16

Conclusions from Testing of TDL CO Analyzer......................................................... 18

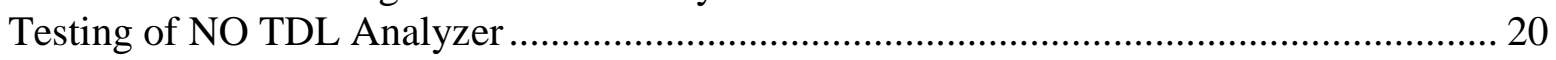

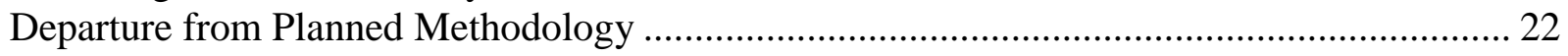

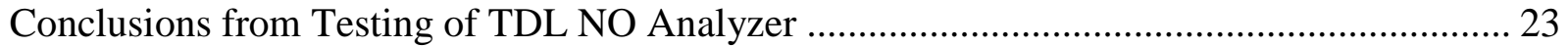

Problems Encountered and Proven or Proposed Solutions for Combustion Zone Analysis .... 23

Departures from Planned Methodology and Impact ........................................................... 24

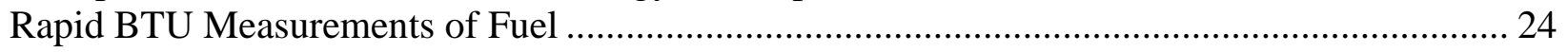

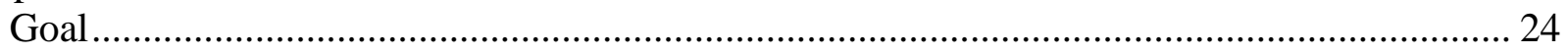

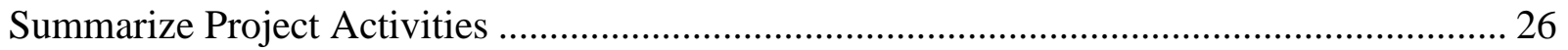

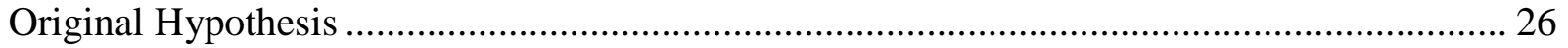

Multi-wavelength Filter NIR ......................................................................... 26

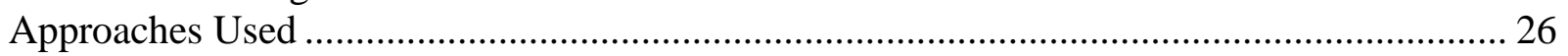

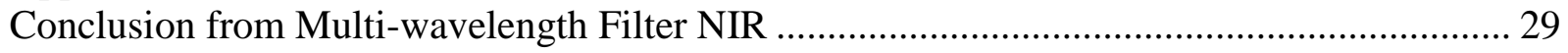

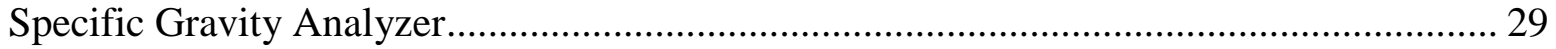

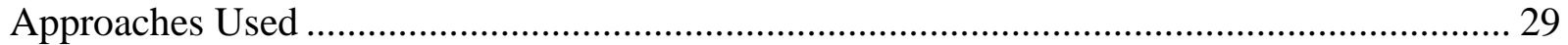

Conclusion from Specific Gravity Analyzer.............................................................. 32

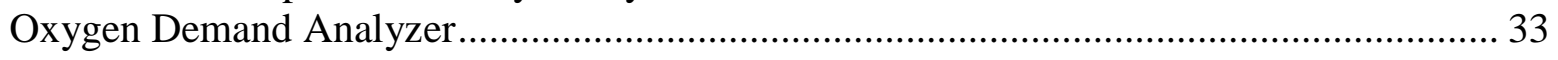

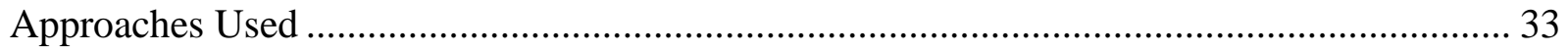

Conclusion for Oxygen Demand Analyzer .............................................................. 35

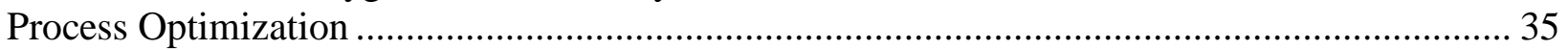




\section{Table of Figures}

Figure 1. Concept of Advanced Combustion Diagnostics for Fired Equipment ......................... 7

Figure 2. Front View of Furnace CFD Model ........................................................................... 9

Figure 3. Side View of Furnace CFD Model (showing probe location) ..................................... 9

Figure 4. TDL Installation Nozzles (typical installation before modification for long path) ...... 10

Figure 5. Fully installed TDL Detect (top) and Launch (bottom) Units .................................. 11

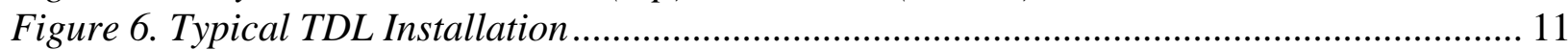

Figure 7. Diverging Laser Beam ........................................................................................... 12

Figure 8. TDL Detector Showing Large Receiver Optics.................................................... 12

Figure 9. Laser Power Transmission during Furnace Startup .................................................. 13

Figure 10. Comparison of Zirc (Point Sensor) versus TDL (Path Sensor) ............................... 14

Figure 11. TDL $\mathrm{O}_{2}$ Analyzer versus $\mathrm{ZrO}_{2}$ Analyzer Performance at Low $\mathrm{O}_{2}$ Level.................... 15

Figure 12. Small CO Breakthrough "Pulses" Corresponding to Small Change in Excess Air ... 17

Figure 13. Large CO Breakthrough at Low Excess Air .......................................................... 17

Figure 14. Comparison of Traditional CO Analyzers versus TDL CO Analyzer....................... 18

Figure 15. Comparison of TDL Path CO Measurement with Sensor Based Point CO

Measurement During Low Excess $\mathrm{O}_{2}$ Excursions .................................................................. 19

Figure 16. HITRAN Spectra of $\mathrm{NO}$ and $\mathrm{H}_{2} \mathrm{O}$ at Combustion Conditions.................................. 21

Figure 17. Field Spectra from Survey at 1790.2nm, Absorption Peaks are from $\mathrm{NO}$ and $\mathrm{H}_{2} \mathrm{O} \ldots 21$

Figure 18.Comparison of Process Spectra over a spectral range of approximately $1790.1 \mathrm{~nm}$ to

$1790.4 \mathrm{~nm}$. It was difficult to specify the true wavelength range because the actual $\mathrm{H} 2 \mathrm{O}$

absorption at furnace temperatures doesn't correspond directly to Hitran database (moisture). 22

Figure 19. Comparison of Excess $\mathrm{O}_{2}$ TDL Reading versus CEMS NOx Reading ...................... 23

Figure 20. A picture of the Axsun NIR IntegraSpec Micro Spectrometer ................................... 26

Figure 21. Axsun Bench and Selectively Heating Sample cell. A) Absorbance Spectra. B)

Standard Deviations of Absorbance. .................................................................................. 28

Figure 22. Net Heating Value versus Relative Density for Selected Gases............................... 30

Figure 23. Emerson Solartron 3098 Specific Gravity Fuel Gas Analyzer ................................. 31

Figure 24. Texas Furnace Average Fuel Gas Composition and Range ................................... 31

Figure 25. Freeport Furnace Fuel Gas Net Heating Value versus Relative Density.................. 32

Figure 26. Densitometer Quantitative Relative Error Associated with $\mathrm{CO}$ and $\mathrm{N}_{2}$ in Fuel

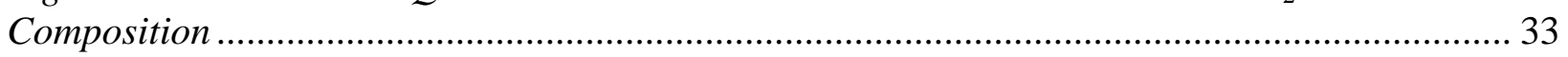

Figure 27. Hobré Instruments Wobbe Index Analyzer ....................................................... 33

Figure 28. Operational Schematic of an Hobre Wobbe Analyzer ............................................. 34

Figure 29. Hobre Wobbe Index Analyzer Calorific Value and Relative Measurement \% Error 35

Figure 30. Schematic Olefin Furnace Major Model Inputs .................................................. 36

Figure 31. Schematic of Furnace Configuration and Cracking Parameters ............................. 36

Figure 32. Typical Furnace Configuration and Operational Constraints ................................ 37

Figure 33. Combustion Process Optimal Efficienc. Optimal Efficiency for most combustion processes is near the stoichiometric ratio of air-to-fuel. The ideal condition is not steady-state and can change due to a number of variables including fuel-types, aging burners and equipment,

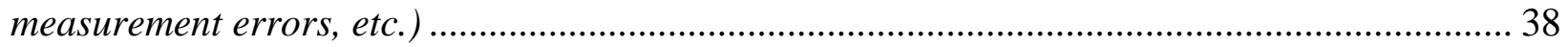

Figure 34. CEMS NOx Emission Level versus Lower Excess $\mathrm{O}_{2}$ Control Set Point .................... 39 


\section{Project Goals \& Accomplishments:}

Provide a comparison of the actual accomplishments with the goals and objectives of the project

\section{Phase I Stages}

\section{Concept Development Overview}

- Individual Analyte Profiles will entail the development of combustion analyzers for oxygen, carbon monoxide and nitric oxide to meet the conditions of the olefins furnace chosen for field testing. The first stage will be pre-field integration and testing, second stage is field installation both in the furnace outlet and above individual burner zones.

- Fuel Feed Analysis will entail the development of a fast $(<20$ second $)$ analysis of major components in the furnace fuel feed. The first stage will be pre-field integration and testing, second stage is field installation and monitoring of the fuel feed to the furnace.

- Process Optimization in phase one will entail manual adjustments to the burners, fuel feed and air feed. The data will be statistically compared to important furnace parameters used to control the process, such as coil-outlet temperature, fan speed, firing rates, severity, etc.. These results should give insight as to which variables should be manipulated by the controller to achieve optimization of the furnace. A step change in certain process inputs will be induced (e.g., fuel BTU) and the outputs will be monitored and correlated.

\section{Phase II Stages}

\section{Validation and Technology Development Overview}

- Phase II will see field installation of the integrated analyte profile, while the measurements will be similar to those in Phase I, the combustion analysis will be performed by a single integrated system in order to reduce purchase and installation costs.

- Phase II will also entail field installation of the fuel feed analysis system. Data will be reviewed to correlate the fuel analysis to coil outlet temperature, severity, fuel consumption and combustion by-products.

- Process Optimization in Phase II will entail the integration of the advanced measurements as inputs to the furnace model used to control and optimize the furnace.

- Dow chose not to pursue Phase II. 
Table 1. Summary of Project Tasks

\begin{tabular}{|c|c|c|}
\hline Task & Dow/ASI & Phase \\
\hline Combustion Zone Analysis & ASI-lead & III \\
\hline Individual Analyte Profiles & & 1 \\
\hline CO measurement development & ASI & 1 \\
\hline CO Furnace Output & Dow & 1 \\
\hline Co Burner Zone & ASI & 1 \\
\hline NO measurement development & Dow & 1 \\
\hline NO Furnace Output & ASI & 1 \\
\hline NO Bumer Zone & Dow & 1 \\
\hline $\mathrm{O} 2$ measurement development & ASI & 1 \\
\hline O2 Furnace Output & ASI & 1 \\
\hline O2 Bumer Zone & Dow & 1 \\
\hline Correlation of Analytical Meausurements to Process Control & Dow-lead & VIII \\
\hline Integrated Analyte Profile & ASI-lead & V/II \\
\hline Offline measurement development & ASI & VIII \\
\hline Burner zone testing & Dow & ॥ \\
\hline Fuel Feed Analysis & & $1 / 11$ \\
\hline Offline measurement development & ASI & 1 \\
\hline Furnace testing & Dow & I/II \\
\hline Process Optimization & Dow-lead & $1 / 1 \mid$ \\
\hline
\end{tabular}

\section{Combustion Zone Analysis}

This project leveraged the success of a completed, DOE funded, project by Dow and ASI (Analytical Specialties Inc.). During the previous project we developed an in-situ tunable diode laser (TDL) analyzer platform. This platform has been tested and proven in a number of combustion processes within Dow and outside of Dow following commercialization.

With the developed platform in place, Phase I of the project focused on adding measurement capabilities such as NO (ppm analysis at combustion zone temperatures), CO (ppm analysis at combustion zone temperatures). Phase I work on the TDL measurements also focused on practical field operability issues such as:

- Maintaining alignment of the laser beam (between laser and detector) over long distances found in modern ethylene cracking furnaces.

- Measurement of the Carbon Monoxide at high temperatures and in the presence of typical combustion gas composition when burning mixed fuels. Mixed fuels typically have large and varying amounts of $\mathrm{H}_{2}$, this leads to large levels of $\mathrm{H}_{2} \mathrm{O}$, which can have a spectral interference with the $\mathrm{CO}$ measurement.

- Adjusting measurement speed to allow real time analysis and control of the ethylene furnace.

For Phase II of the project we planned to develop advancements in the platform itself. These included:

- Development of a multi-gas, multi-path measurements within one analytical package. Specifically analysis of low $(<50 \mathrm{ppm})$ levels of $\mathrm{CO}$ and $\mathrm{NO}$.

- Installation and testing of the multi-path measurement system in 2-4 burner zones (determined by Phase I data analysis) and the furnace crossover section.

Table 2. Comparison of Actual Accomplishments with Project's Goals/Objectives 
Task

Goal

Actual Accomplishment

1. Combustion Zone Analysis: In situ, real time analysis of combustion process to enable advanced control.

\begin{tabular}{|c|c|c|}
\hline $\begin{array}{l}1.1 \text { Individual Analyte } \\
\text { Profiles }\end{array}$ & & \\
\hline $\begin{array}{l}1.1 .1 \mathrm{CO} \text { measurement } \\
\text { development }\end{array}$ & $\begin{array}{l}\text { Sub-ppm sensitivity under } \\
\text { process conditions. } \\
\text { Measurement speed } \\
<10 \text { seconds. } \\
\text { Measurement availability }>95 \%\end{array}$ & Completed as proposed. \\
\hline 1.1.2 CO Furnace Output & Field validation of measurement & Completed as proposed \\
\hline 1.1.3 CO Burner Zone & Field validation of measurement & $\begin{array}{l}\text { Not required. After CFD (computational fluid } \\
\text { dynamic) analysis it was determined that the } \\
\text { crossover section of the furnace (Furnace } \\
\text { Output) represented the conditions in the } \\
\text { burner zone. All burner zone measurements } \\
\text { were not required for project success. }\end{array}$ \\
\hline $\begin{array}{l}\text { 1.1.4 NO measurement } \\
\text { development }\end{array}$ & $\begin{array}{l}\text { 10-ppm sensitivity under process } \\
\text { conditions. Measurement speed } \\
<10 \text { seconds. } \\
\text { Measurement availability }>95 \%\end{array}$ & $\begin{array}{l}\text { Pre-field development completed. } \\
\text { Proceeded to field testing. }\end{array}$ \\
\hline 1.1.5NO Furnace Output & Field validation of measurement & $\begin{array}{l}\text { Task failed. During field testing it was } \\
\text { determined that } \mathrm{H} 2 \mathrm{O} \text { absorbance } \\
\text { overwhelmed the } \mathrm{NO} \text { absorbance peak. }\end{array}$ \\
\hline 1.1.6 NO Burner Zone & Field validation of measurement & Not required \\
\hline $\begin{array}{l}1.1 .7 \mathrm{O} 2 \text { measurement } \\
\text { development }\end{array}$ & $\begin{array}{l}2000-\text {-ppm sensitivity under } \\
\text { process conditions. } \\
\text { Measurement speed } \\
<10 \text { seconds. } \\
\text { Measurement availability }>95 \%\end{array}$ & Completed as proposed \\
\hline 1.1.8 O2 Furnace Output & Field validation of measurement & Completed as proposed \\
\hline 1.1.9 O2 Burner Zone & Field validation of measurement & Not required \\
\hline \multicolumn{3}{|c|}{$\begin{array}{l}\text { 2.0 Correlation of Analytical Measurements to Process Control: } \\
\text { Identify which control variables are most correlated to changes in the new measurement (inputs) }\end{array}$} \\
\hline $\begin{array}{l}2.1 \text { Integrated Analyte } \\
\text { Profile }\end{array}$ & $\begin{array}{l}\text { In-situ real time analysis with low } \\
\text { cost multi-path, multi-gas } \\
\text { integrated analytical system. }\end{array}$ & $\begin{array}{l}\text { Multi-path measurements were not needed } \\
\text { (proven by CFD analysis and statistical } \\
\text { analysis of measurement data). } \\
\text { Multi-gas measurement completed. } \\
\text { Cost objective met, although different than } \\
\text { original concept. }\end{array}$ \\
\hline $\begin{array}{l}\text { 2.1.1 Offline } \\
\text { measurement } \\
\text { development }\end{array}$ & $\begin{array}{l}\text { Sub-ppm sensitivity under } \\
\text { process conditions. } \\
\text { Measurement speed } \\
<10 \text { seconds. } \\
\text { Measurement availability }>95 \%\end{array}$ & Not required \\
\hline 2.1.2 Burner zone testing & Field validation of measurement & Not required \\
\hline
\end{tabular}




\section{Summarize Project Activities}

\section{Combustion Zone Analysis}

\section{Cracking Furnace}

\section{Advanced Measurements In the Combustion Zone:}
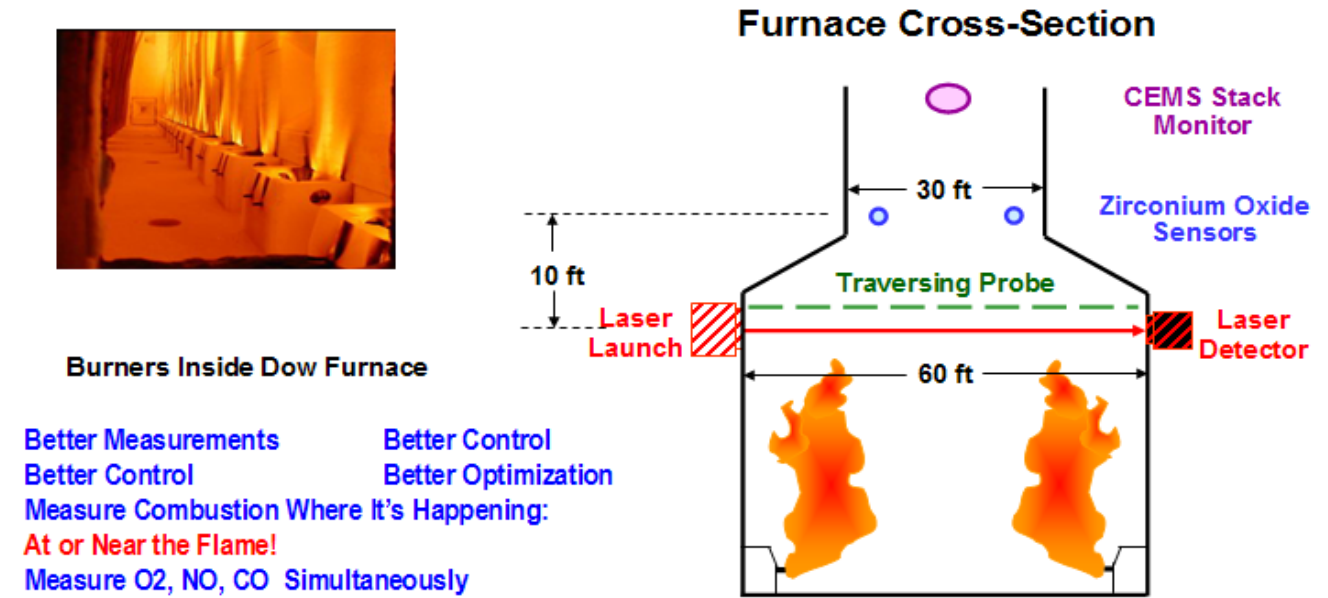

Better Measurements

Better Control

Better Control Better Optimization

Measure Combustion Where It's Happening:

At or Near the Flame!

Measure 02, NO, CO Simultaneously

Figure 1. Concept of Advanced Combustion Diagnostics for Fired Equipment

This project leveraged the success of a completed, DOE funded, project by Dow and ASI. During the previous project we developed an in-situ tunable diode laser (TDL) analyzer platform. This platform has been tested and proven in a number of combustion processes within Dow and since commercialization outside of Dow.

With the developed platform in place, Phase I of the project focused on adding measurement capabilities such as NO (ppm analysis at combustion zone temperatures), CO (ppm analysis at combustion zone temperatures), and $\mathrm{O}_{2}$ ( $\%$ analysis at combustion zone temperatures), see

Phase I work on the TDL measurements also focused on practical field operability issues such as:

- Maintaining alignment of the laser beam (between laser and detector) over long distances found in modern ethylene cracking furnaces.

- Measurement of the Carbon Monoxide at high temperatures and in the presence of typical combustion gas composition when burning mixed fuels. Mixed fuels typically have large and varying amounts of $\mathrm{H}_{2}$, this leads to large levels of $\mathrm{H}_{2} \mathrm{O}$, which can have a spectral interference with the $\mathrm{CO}$ measurement.

- Adjusting measurement speed to allow real time analysis and control of the ethylene furnace.

Goal

One of the goals of this project was to develop and in-situ, real time analysis of combustion process to enable advanced control and optimization of fired-equipment. The concept is illustrated in Figure A. As a main deliverable, long-path measurements using tunable diode laser (TDL) technology will be installed, tested and evaluated in a modern large-scale ethylene furnace. A thorough assessment of the ability to use these advanced measurements for optimizing and controlling a furnace will also be 
carried out. Estimated installation costs of $<\$ 50,000$ for older/smaller ethylene furnaces up to $\$ 100,000$ for newer/larger furnaces are estimated.

\section{Original Hypothesis}

TDL Technology is capable of measuring $\mathrm{O}_{2}$ (low \% level), CO (low ppm level) and NO (mid ppm levels) at combustion temperatures during full operation of an ethylene furnace. These measurements would offer the advantages (over current technology):

- Speed to allow the measurement to correctly indicate process conditions (5 seconds)

- Representative of the process conditions by measuring across a large section of the furnace versus point sensors currently used

- Accuracy (no or low interferences from other combustion gas components)

- Sensitivity (low ppm measurement of CO, mid ppm measurement of NO)

- Measurements at high temperatures (especially critical for CO which "after-burns" as it travels further from the high temperature furnace zone)

Basic assumptions of the combustion gas measurement goals were as follows:

- Significant structural and architectural changes would be needed to maintain measurement during furnace temperature changes (start up, shut down and decoke operations). With larger furnaces the physical movement of the furnace walls would cause the laser beam to lose contact with the detector installed on the opposite end of the furnace. This proved to be correct.

- Low ppm sensitivity and accuracy not currently achievable would be needed for the CO measurement in order to control the furnace with low excess air/oxygen (maximum energy efficiency). This proved to be correct.

- Other combustion by-products would interfere with the CO measurement (spectral overlap). This proved to be correct.

- To deliver a representative measurement it would be necessary to provide multiple measurement paths for each analyte $\left(\mathrm{O}_{2}, \mathrm{CO}, \mathrm{NO}\right)$. This proved to be incorrect.

- To meet cost goals (\$50-100,000 installation costs) it would be necessary to develop a multiplexed laser system that would split one laser into multiple measurement paths. This proved to be incorrect. At the time of the project inception a single CO laser cost $\sim \$ 10,000$ USD.

\section{Approaches Used}

\section{CFD Modeling}

One of the first actions was to use Computational Fluid Dynamic Modeling (CFD modeling) to determine the correct placement of the measurement. CFD is one of the branches of fluid mechanics that uses numerical methods and algorithms to solve and analyze problems that involve fluid flows. Computers are used to perform the millions of calculations required to simulate the interaction of liquids and gases with surfaces defined by boundary conditions. CFD models are available for modern ethylene processes and are typically used to design furnace geometry and burner placement. Figure 2 and Figure $\mathbf{3}$ are data that estimate where the recirculation zones for the furnace used in the field trial.

For the purposes of this project CFD modeling would allow us to determine the optimum placement of the analyzer so that the measurement path (laser beam path) would represent the process.

The following assumptions were used for the CFD modeling:

$\checkmark$ Fuel 8682 \#/hr

$\checkmark$ Excess $\mathrm{O}_{2} 2.69 \%$

$\checkmark$ Velocity $13.944 \mathrm{~m} / \mathrm{s}$

$\checkmark$ Density $.2457 \mathrm{~kg} / \mathrm{m}^{\star *} 3$

$\checkmark$ Flue gas is pre-burned

$\checkmark$ All flue gas enters through floor burners 
$\checkmark$ Stack gas 181,922 \#/hr

$\checkmark$ Temperature $1377.7 \mathrm{~K}$

$\checkmark$ Convection section internals have no effect on flow No tramp air

$\checkmark$ Uniform velocity, temperature \& composition
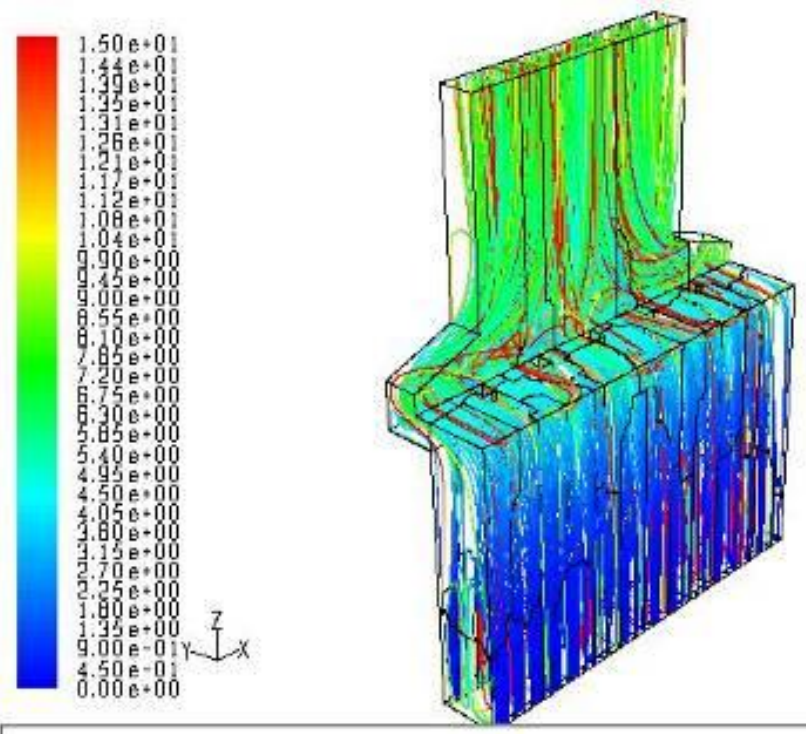

Particle Traces Eolored by Particle Residence Time

Apr B4, $200 \mathrm{~B}$ FLUENT B.2 [3d, dp, segregated, ske]

Figure 2. Front View of Furnace CFD Model

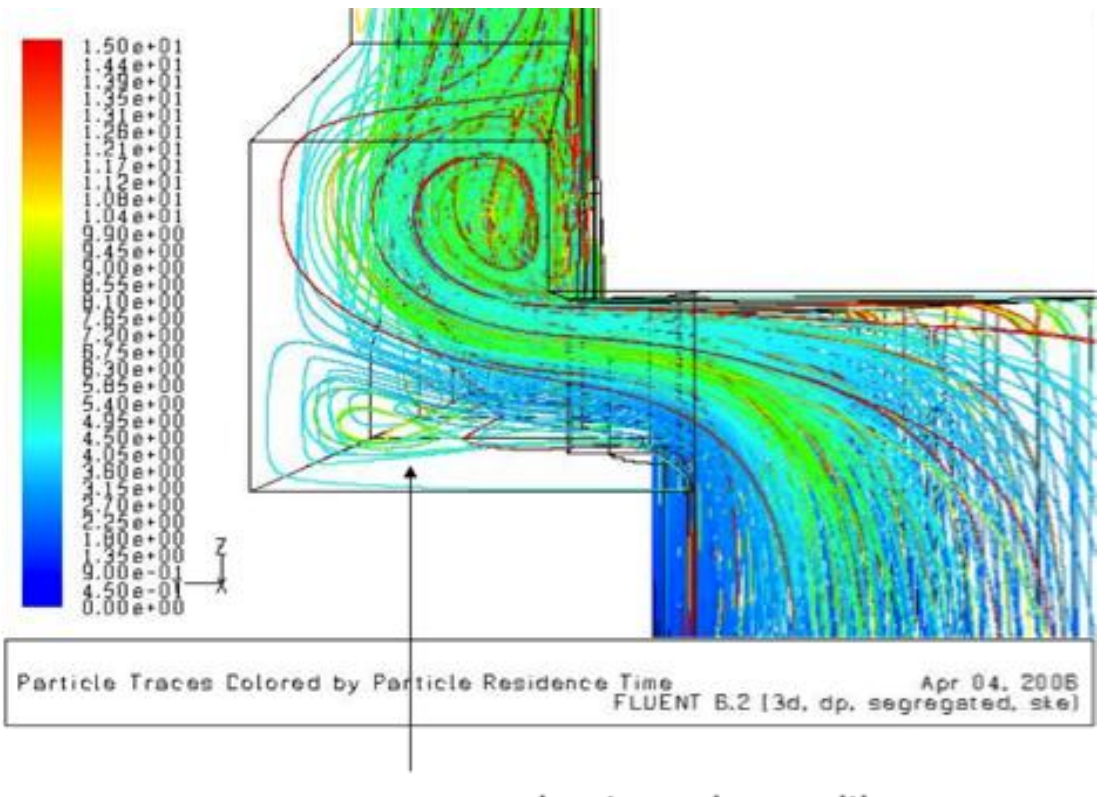

approximate probe position

Figure 3. Side View of Furnace CFD Model (showing probe location)

\section{Conclusion}


Representative sampling in firebox will be difficult due to strong jetting and strong recirculation. The ideal location of the measurement will be inside a recirculation zone. This will result in a loss of sensitivity since the burner output will be mixed. This location will provide a representative analysis of the furnace firebox. For the proposed furnace installation the best locations is as high as possible in access doors.

\section{Installation of TDL $\mathrm{O}_{2}$ and $\mathrm{CO}$ Analyzers}

The next approach was to design and install individual TDL analyzers to measure Oxygen $\left(\mathrm{O}_{2}\right)$, Carbon Monoxide (CO) and Nitric Oxide (NO).

Initially the installation focused on one of the anticipated difficulties, maintaining alignment over a long path (furnace length for this installation was $~ 84$ feet) during temperature induced "wall flex". When the furnace wall flexes around the laser (transmitter) side of the TDL analyzer it causes the laser beam to move, over long distances this movement can be significant enough to cause the laser beam to miss the detector completely.

The $\mathrm{O}_{2}$ analysis in particular is critical during all operation modes of the furnace. Any loss of measurement due to loss of laser beam alignment is unacceptable. In order to maximize the success of this test the following approaches were used:

- Design of the TDL nozzles.

During furnace temperature changes, the walls of the furnace deform. Furnace temperature changes can occur suddenly, i.e. during a rain storm, or slowly, i.e. during furnace start up or shut down or during furnace decoke.

Dow Chemical designed a bracing structure that would minimize the movement of the TDL installation nozzle during furnace wall flex.

Error! Reference source not found. shows the TDL flanges prior to modification. Dow designed a simple, low cost design to minimize the effects of wall flex during furnace temperature changes. The result is an accessible TDL nozzle for installation of the block valve and TDL launch or detect unit (Figure 4).

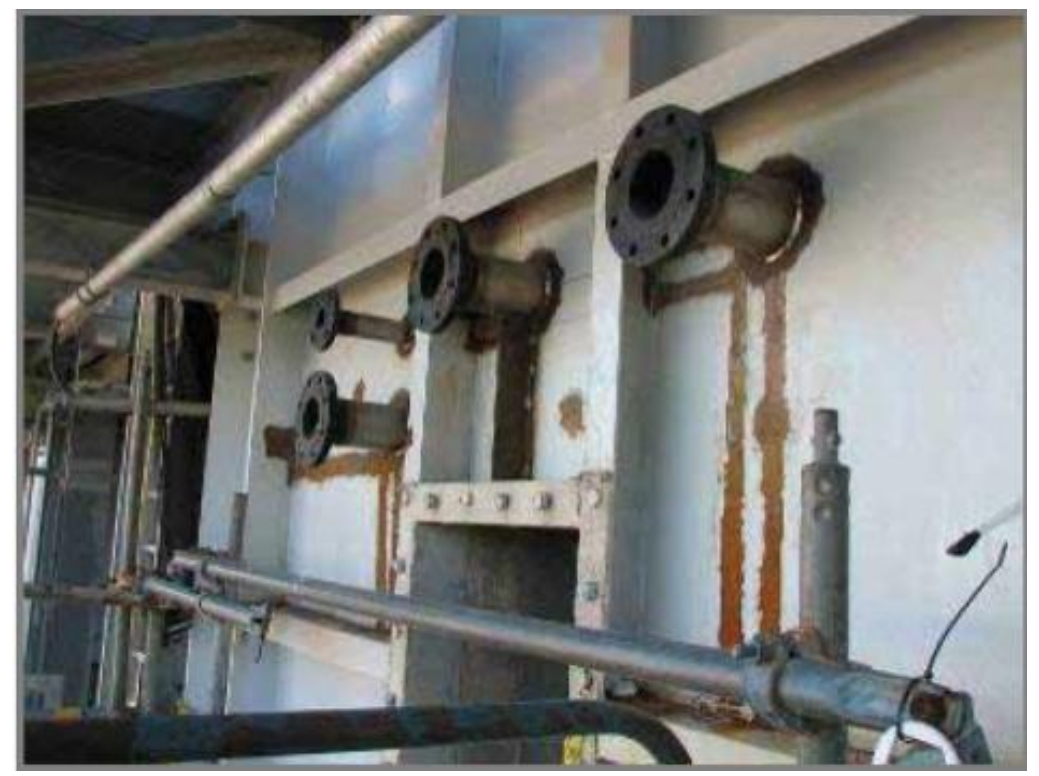

Figure 4. TDL Installation Nozzles (typical installation before modification for long path) 


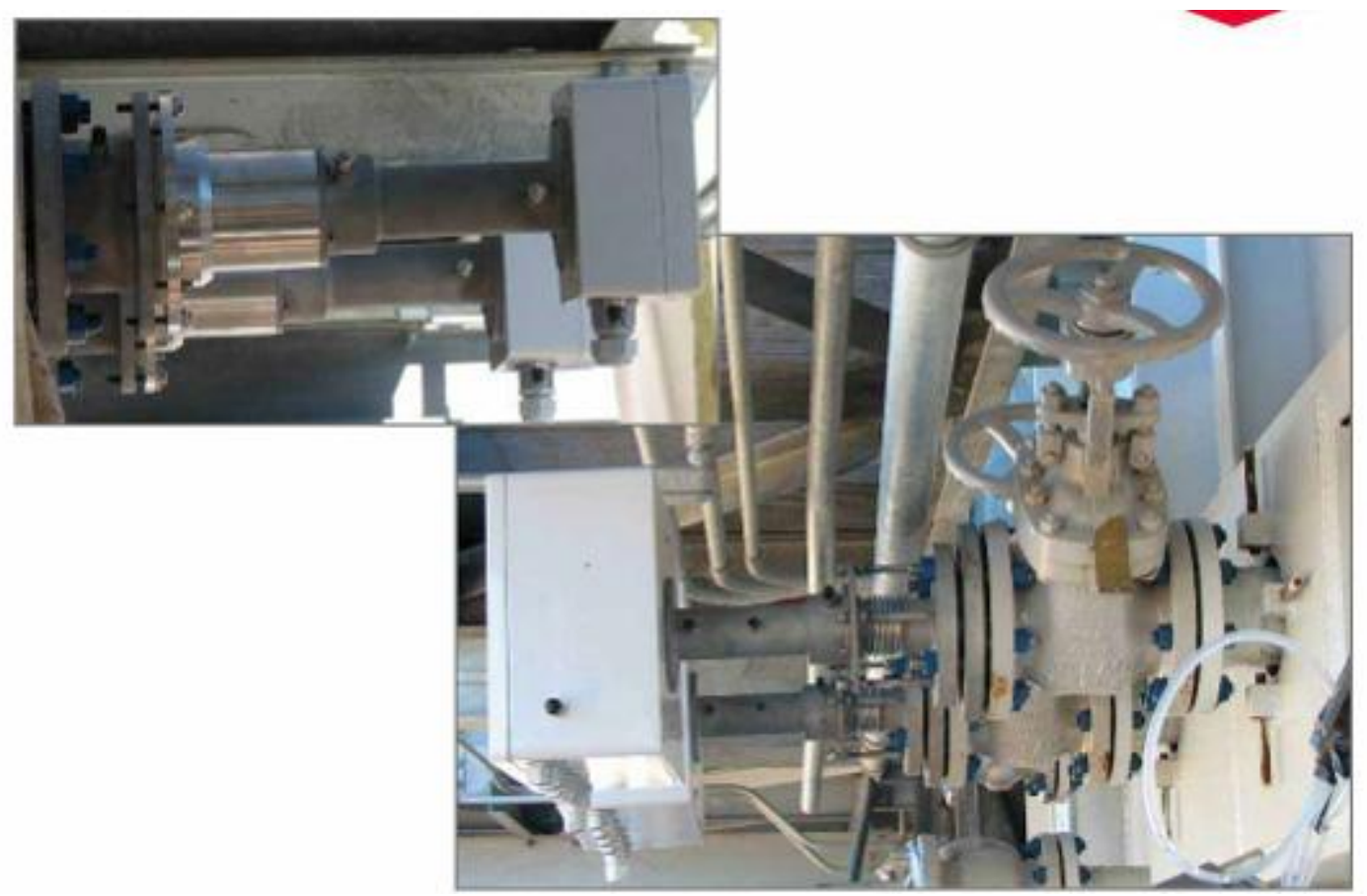

Figure 5. Fully installed TDL Detect (top) and Launch (bottom) Units

A typical TDL installation uses a tightly collimated laser beam. The beam diameter is approximately $15-25 \mathrm{~mm}$. This allows all of the laser beam power to be focused on the receiver. This is shown in Figure 6. The TDL installation nozzles and flanges are shown in red for illustration purposes.

For this test installation the TDL was supplied with a diverging laser beam, shown in Figure 7. As the laser beam travels from the transmitter the diameter increases. The approximate diameter of the laser for this installation was 24 " at the detector side of the furnace.

This configuration allows significant movement of the laser beam center axis ("I" in Figure 7) when compared to a tightly collimated beam. The disadvantage is that the laser power density at the detector collimating lens is significantly less than with a tightly collimated beam.

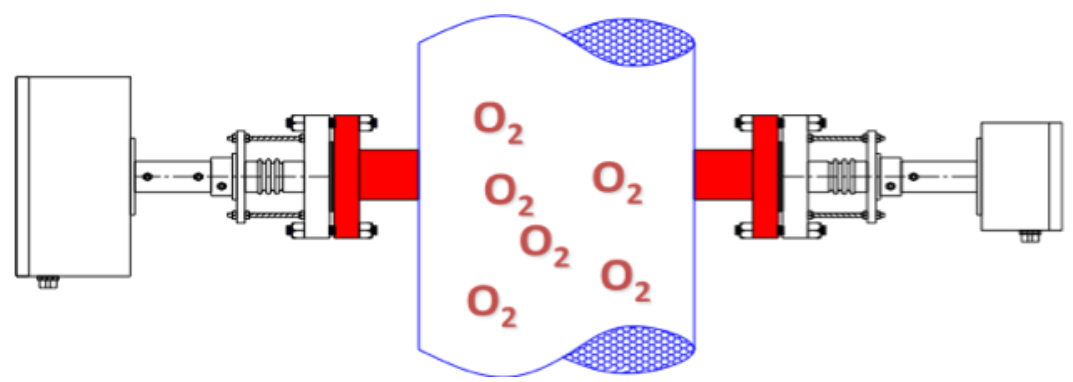

Figure 6. Typical TDL Installation 


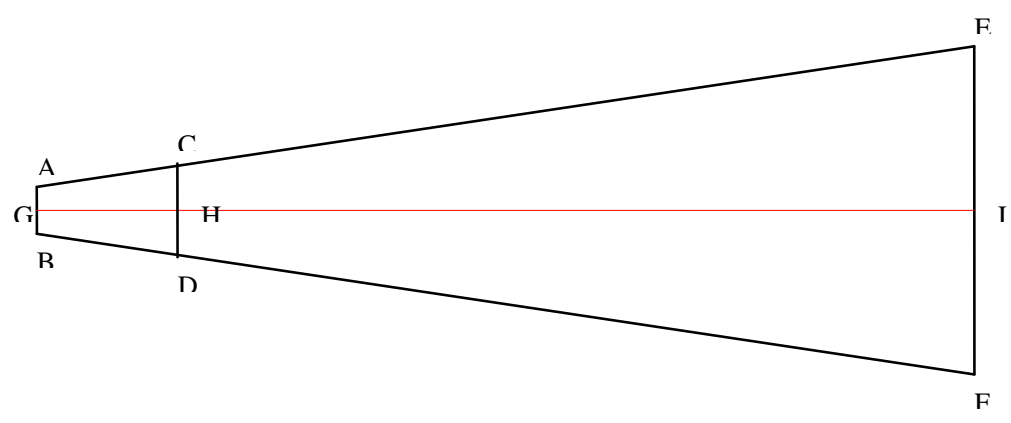

Figure 7. Diverging Laser Beam

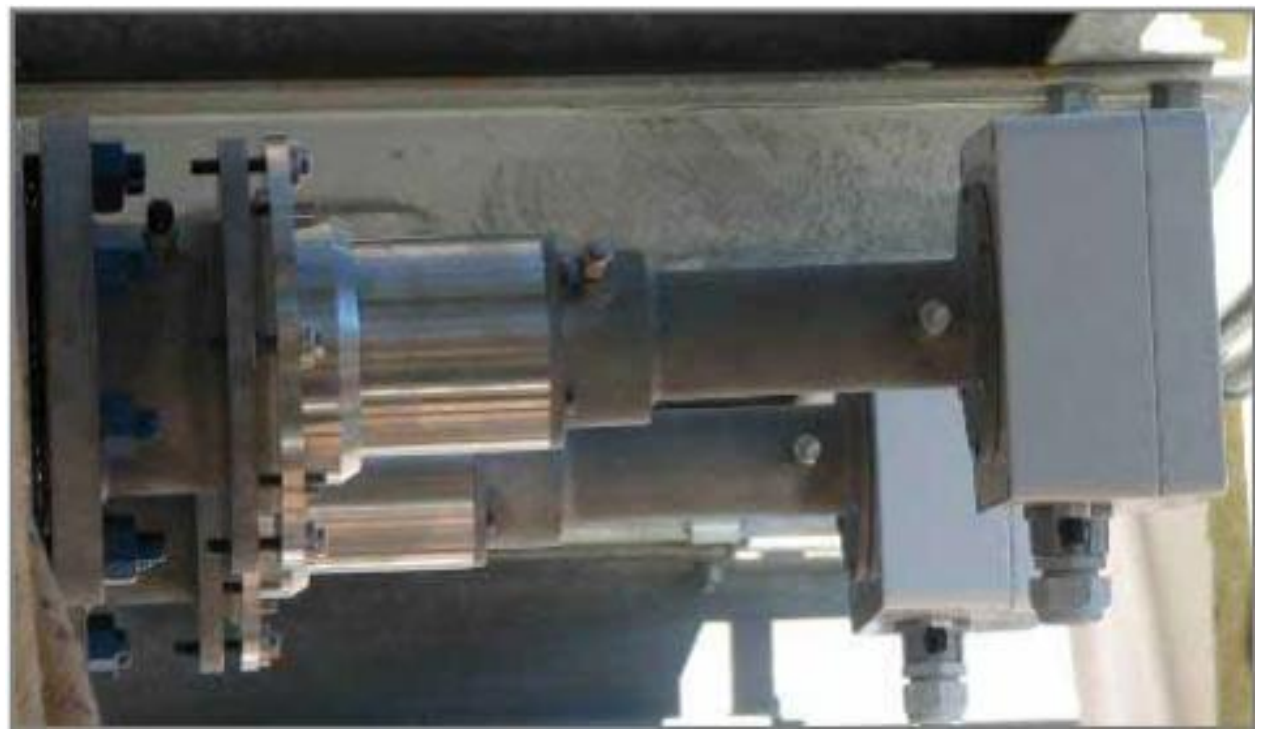

Figure 8. TDL Detector Showing Large Receiver Optics

- Use of a large area detector (receiver) focusing lens optical element, shown in Figure 8.

In order to compensate for the loss of laser power density a larger process and window were used on the detector side of the TDL. Typically a $25 \mathrm{~mm}$ diameter window and collimation lens are used. For this installation we installed a 4" diameter process window and collimation lens, allowing more laser power to be focused on the detector. This window is especially important when the furnace is in decoke and particulate may be present in the laser beam path (blocking laser light).

\section{Conclusions From Installation of $\mathrm{TDL} \mathrm{O}_{2}$ and $\mathrm{CO}$ Analyzers}

As shown Figure 5, after design improvements of both the TDL analyzer and the installation, the analyzer was capable of maintaining alignment and measurement during furnace start up conditions. Testing was also conducted during decoke operations with success.

Overall during the final 3 month test period of the installation the TDL analyzers maintained $100 \%$ uptime with no loss of laser power transmission (alignment) or measurement, as illustrated in Figure 9. 


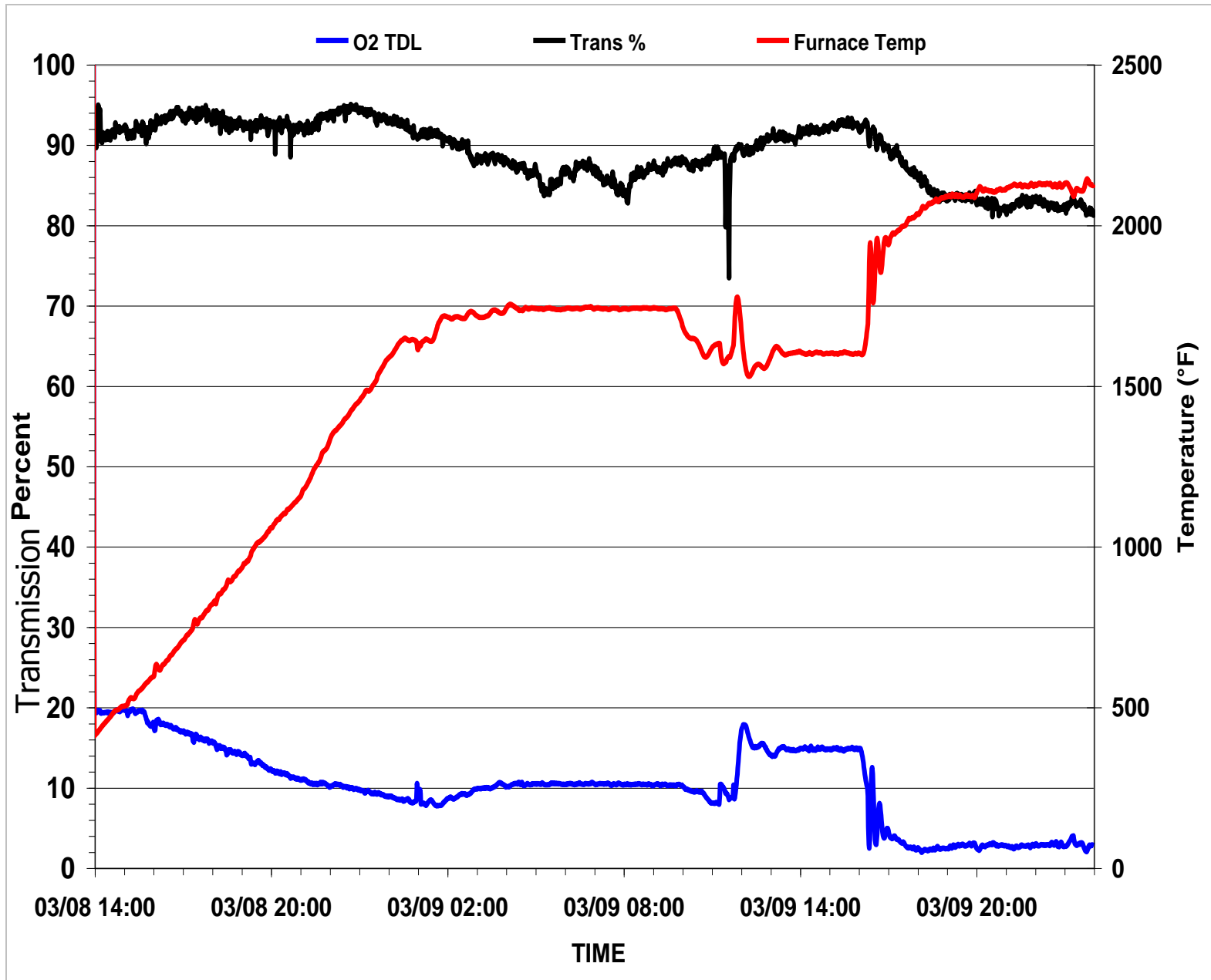

Figure 9. Laser Power Transmission during Furnace Startup

\section{Testing of $\mathrm{O}_{2}$ TDL Analyzer}

Once the operability of the TDL $\mathrm{O}_{2}$ analyzer was proven, the next step was to compare the use of a TDL (long-path) measurement to the more conventional point measurement based on zirconimum oxide. The most important aspect of the TDL $\mathrm{O}_{2}$ analyzer as compared to existing technology is the ability to measure a cross section of the furnace, resulting in a more representative analysis. Traditional zirconia oxide sensors $\left(\mathrm{ZrO}_{2}\right)$ are point measurements, they only sample a small (3/8") section of the furnace. Due to burner-burner variations it is known that the distribution of oxygen in the furnace is significant.

During the project the TDL $\mathrm{O}_{2}$ analyzer (1 path sensor) was compared to the installed $\mathrm{ZrO}_{2}$ analyzers (2 point sensors). Frequently the TDL analyzer reading would differ from each of the $\mathrm{ZrO}_{2}$ sensors. This was expected due to the burner variations which induce gradients for $\mathrm{O}_{2}$. Typical comparison data is shown in

\section{Figure}

The most significant comparative data came during furnace step change testing when the excess $\mathrm{O}_{2}$ levels were reduced below $1.0 \%$. This condition is a critical region since the original hypothesis of the project was that modern ethylene furnaces could be operated at lower excess $\mathrm{O}_{2}$ levels, improving energy efficiency. Below $0.8 \%$ excess $\mathrm{O}_{2}$ the traditional $\mathrm{ZrO}_{2}$ sensors were extremely unstable ( as 
demonstrated in Figure 11), essentially unusable. The TDL $\mathrm{O}_{2}$ analyzer was able to maintain measurement at the lowest levels tested $\left(0.6 \%\right.$ excess $\left.\mathrm{O}_{2}\right)$.

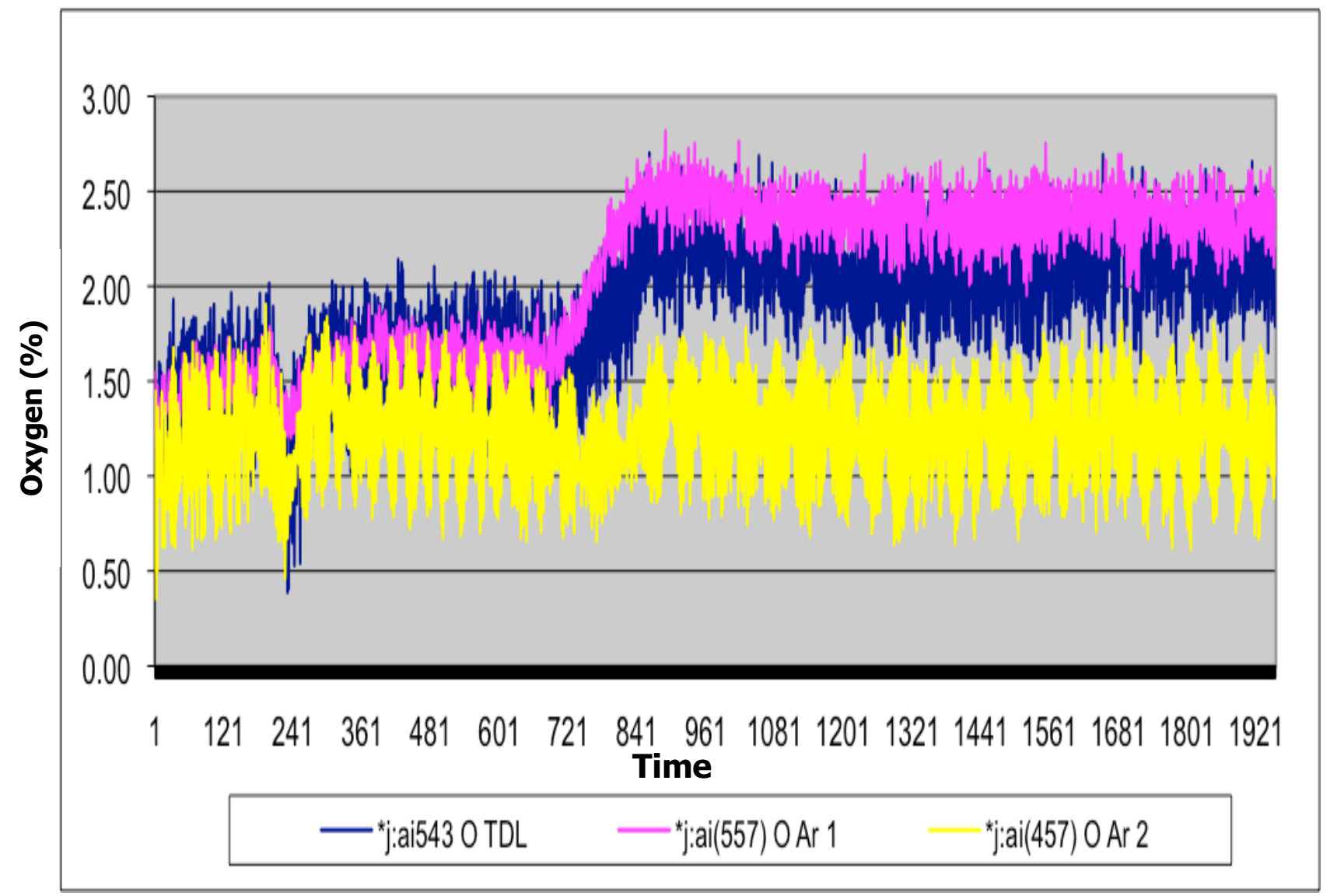

Figure 10. Comparison of Zirc (Point Sensor) versus TDL (Path Sensor) 


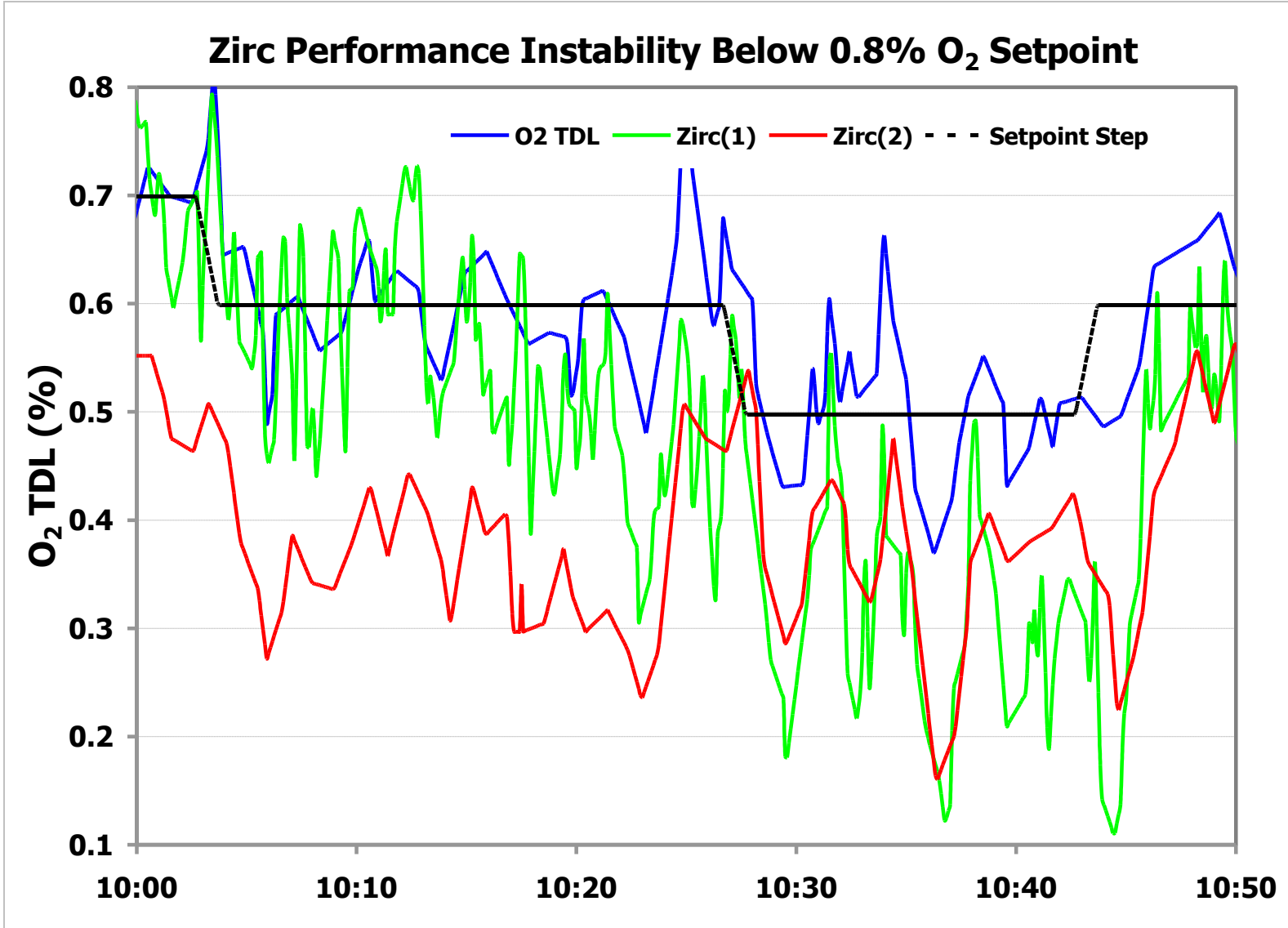

Figure 11. $\mathrm{TDL} \mathrm{O}_{2}$ Analyzer versus $\mathrm{ZrO}_{2}$ Analyzer Performance at Low $\mathrm{O}_{2}$ Level (time on x-axis)

\section{Conclusions from Testing of TDL $\mathrm{O}_{2}$ Analyzer}

The TDL $\mathrm{O}_{2}$ analyzer had reasonable agreement with the modeled results using process parameters. Additionally the TDL $\mathrm{O}_{2}$ analyzer maintained measurement reliability at low excess $\mathrm{O}_{2}$ levels. The ability to measure a large cross section of the furnace (representative measurement) and to measure at low excess $\mathrm{O}_{2}$ is a significant improvement over current $\mathrm{ZrO}_{2}$ based technology.

One significant difference between traditional point $\mathrm{O}_{2}$ measurements and TDL path average measurements is that the path measurement does not provide spatial information. Point sensors provide a measurement at a particular point in the process, this information can be useful in identifying variations in $\mathrm{O}_{2}$ levels that are caused by burner to burner variations (unbalanced burners). However, the industry standard (for refining and chemical furnaces) of installing 1-3 point sensors cannot provide enough spatial information to allow burner balance diagnostics. A modern ethylene furnace can have $>100$ burners, and as shown in the CFD modeling results the resulting $\mathrm{O}_{2}$ gradients are significant. The typical operating mode for a large furnace with multiple point sensors is to "vote low", that is to control from the point sensor with the lowest reading. This is done for safety, particularly since the $\mathrm{CO}$ or "combustibles" sensors used in the point source analyzers are not reliable enough to trust for safety diagnostics (indication of fuel rich operation). The end result is that the furnace will be operated at an excess $\mathrm{O}_{2}$ level based on the lowest $\mathrm{O}_{2}$ reading, not the overall air fuel ratio, this leads to inefficient operation. Further, the long-path measurement is more representative of the conditions inside the equipment where point monitors must be place strategically to get reliable results.

For furnaces with dual zones, such as the test furnace for this project, two $\mathrm{O}_{2}$ measurements are mandatory, one in each zone. Each zone has independent fuel control, as a result the excess $\mathrm{O}_{2}$ level 
must be known in each zone. For these installations Dow will use two TDL based $\mathrm{O}_{2}$ measurements. The justification for two TDL path measurements versus two $\mathrm{ZrO}_{2}$ point measurements is that the path measurement provides a more representative measurement of the air fuel ratio in each zone, and the TDL in general is more reliable, especially at low $\mathrm{O}_{2}$ levels.

\section{Testing of CO TDL Analyzer}

The next approach was to design and install individual TDL analyzer to measure Carbon Monoxide (CO). While the $\mathrm{O}_{2}$ TDL installation showed promising results (improvement of measurement over existing technology), the $\mathrm{CO}$ measurement was the most critical component for the project success. The original hypothesis was that a fast, high temperature, path average $\mathrm{CO}$ measurement would allow identification of the correct furnace setpoint for maximum efficiency and throughput.

The CO test results can be divided into 4 categories:

1. Normal operation

2. Abnormal operation (combustion difficulty)

3. Start up conditions

4. Controlled step changes in the furnace operation

During all 4 phases the $\mathrm{CO}$ measurement can be used for improved control and efficiency as well as safety.

Extensive testing and monitoring was performed during Condition 1 (normal operation). Due to the nature of Condition 2 and 3, the project had to continuously test and monitor the CO TDL to have data results coinciding with these conditions, they do not occur frequently. Fortunately we were also able to capture data during these unusual conditions. Condition 4, Furnace Step Changes, was the final phase of the project. After the Dow operations group gained sufficient confidence in the TDL measurements they agreed to perform a series of controlled furnace step changes at great cost and inconvenience to the ethylene business unit. This data will be analyzed with regards to furnace control modifications later in this report. This section will focus on the measurement performance of the TDL CO analyzer during all 4 Conditions.

\section{Condition $1 \& 2-$ Normal and Abnormal Operations}

Figure \& Figure capture $\mathrm{CO}$ versus $\mathrm{O}_{2}$ (excess air) data that represents both normal and abnormal furnace operation.

In

Figure, the furnace is operating with a relatively normal excess $\mathrm{O}_{2}$ setpoint of $1.3 \% \mathrm{O}_{2}$. During this period (data point 1- 550, with each data point representing 3 seconds) the CO reading is typically between 5 and $10 \mathrm{ppm}$. The measurement noise is very low (sub-ppm), most of the measurement variation during this time is from actual $\mathrm{CO}$ changes in the combustion gas.

At point 550 there is a simultaneous change in the excess $\mathrm{O}_{2}$ (average reduction of $\sim 0.2 \%$ ), at the same time there are clear well defined CO "pulses" that appear in the 15-25ppm range with one large CO spike of approximately 100ppm at data point 805 . These $\mathrm{CO}$ data pulses are indicative of $\mathrm{CO}$ breakthrough in some of the furnace burners. This data clearly shows that the TDL CO analyzer is capable of monitoring $\mathrm{CO}$ changes of $<10 \mathrm{ppm}$ that are directly related to changes in air fuel ratio (reduction in excess air). Also shown at data point 1000, the operator increased the burner air feed resulting in an increase of excess air $\left(\mathrm{O}_{2}\right)$ and a decrease in the CO TDL readings. At data point 1200 the operator reduced burner air, the excess $\mathrm{O}_{2}$ decreased, and again we saw a well defined increase in TDL CO readings.

It is important to note that during the entire period shown in Figure 12, the CO levels were not; 1) above acceptable emissions limits, 2) above safety limits, or 3) large enough to cause efficiency losses. 


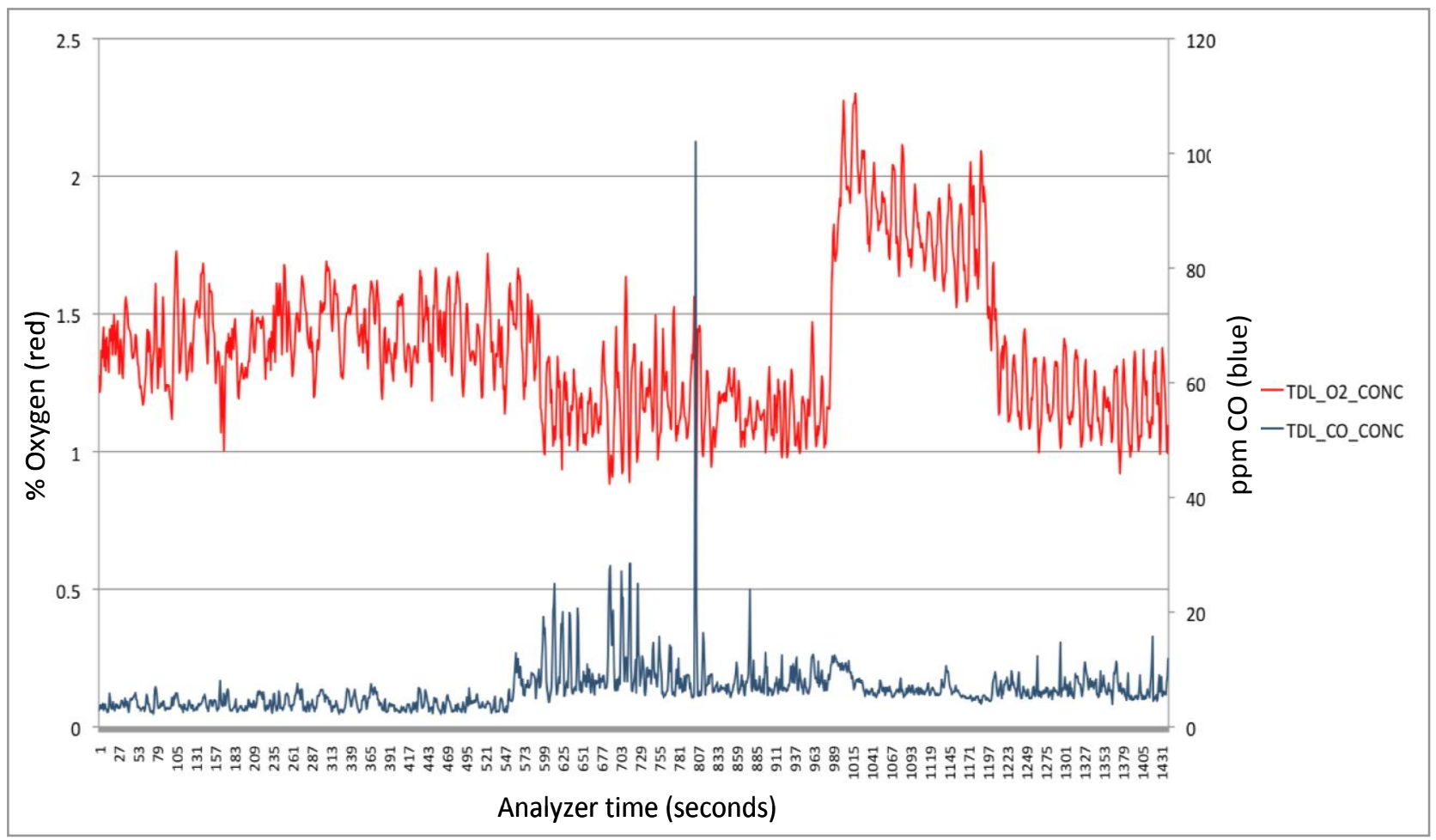

Figure 12. Small CO Breakthrough "Pulses" Corresponding to Small Change in Excess Air

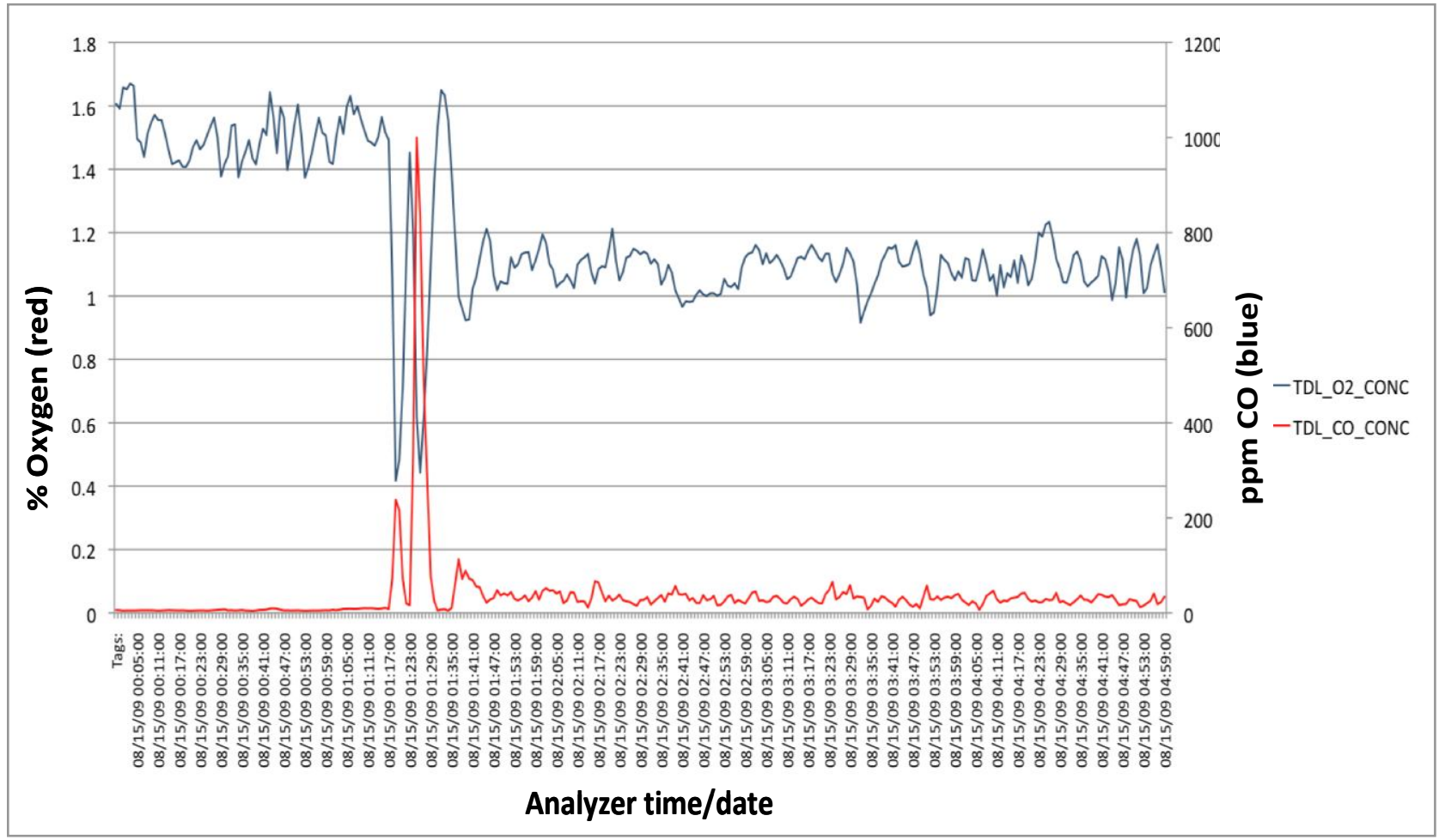

Figure 13. Large CO Breakthrough at Low Excess Air 
Figure 13 shows the TDL CO reading during a large change in air fuel ratio which resulted in a very large decrease of the excess $\mathrm{O}_{2}$ (air) from $\sim 1.5 \%$ to $<0.5 \%$. This is an abnormal condition resulting from a furnace upset condition. During the large decrease in excess air, the TDL CO reading rapidly spiked to $\sim 200 \mathrm{ppm}$ (at 01:17:00) and $1000 \mathrm{ppm}$ (at 01:27:00). The excess $\mathrm{O}_{2}$ then recovers to $\sim 1.1 \%$ at 01:35:00 and the CO readings drop simultaneously to $<50 \mathrm{ppm}$.

This data illustrates the ability of the TDL CO analyzer to rapidly respond to large amounts of $\mathrm{CO}$ burner breakthrough. While neither incident resulted in unsafe $\mathrm{CO}$ levels or $\mathrm{CO}$ levels above emissions limits, if the excess $\mathrm{O}_{2}$ had been reduced further, the furnace could have rapidly reached an unsafe level with emissions limits being exceeded.

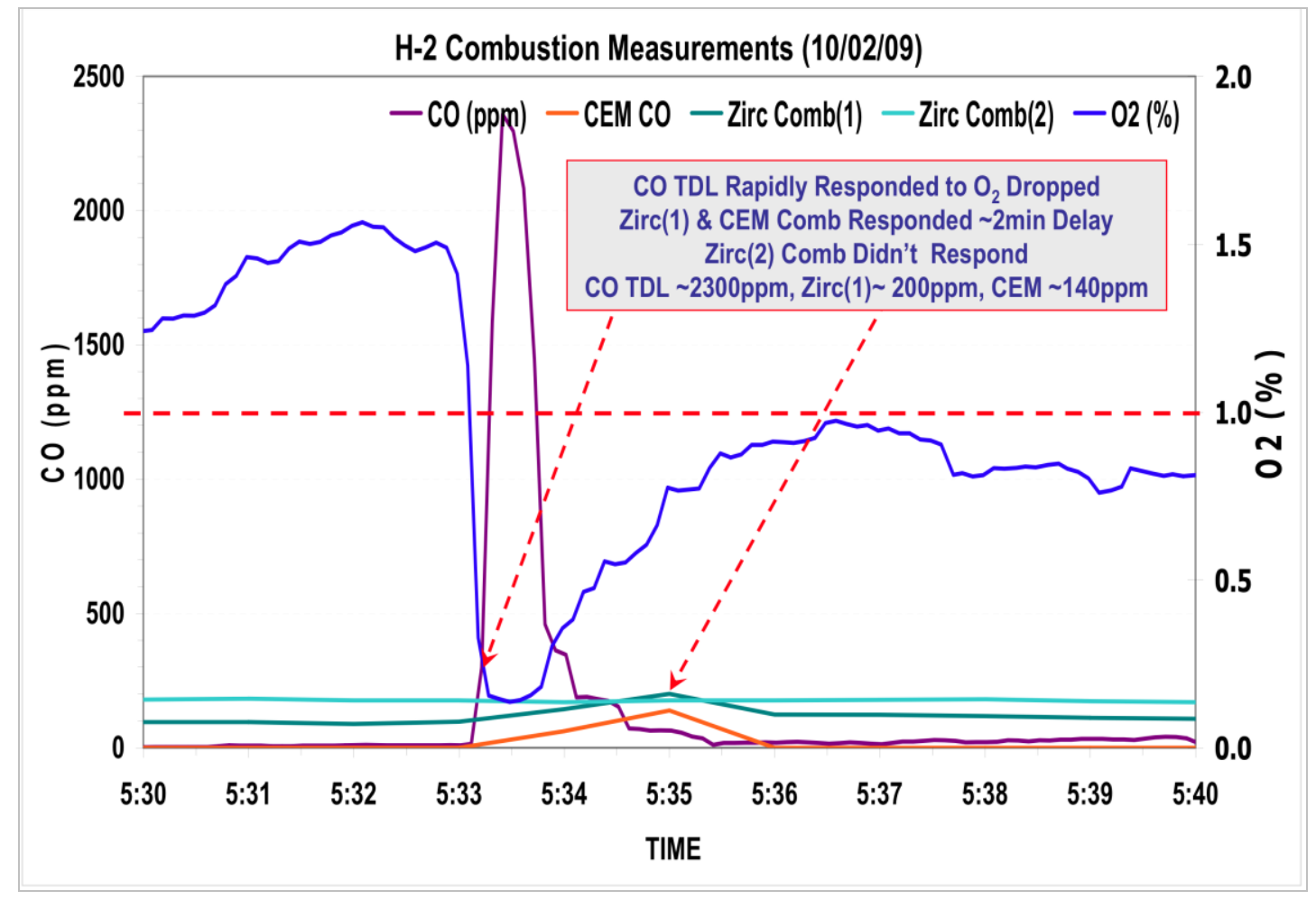

Figure 14. Comparison of Traditional CO Analyzers versus TDL CO Analyzer

During all testing stages a comparison of the TDL CO analyzer was made to the traditional technologies for measuring CO. Figure 14 shows such a comparison. During this event the excess $\mathrm{O}_{2}$ level dropped from $\sim 1.5 \%$ to $<0.5 \%$. It would be expected that during a large change in excess $\mathrm{O}_{2}$ such as this that the $\mathrm{CO}$ from the burners would rise quickly and in significant levels. The main purpose of the CO TDL is to rapidly detect these events and allow a rapid return to safe and efficient control.

In this instance the TDL CO analyzer was compared to the following installed analyzers with results shown below:

- TDL CO analyzer: Simultaneous response with reduction in excess air. CO reported value 2,000ppm

- Stack mounted infrared CO analyzer (CEMS): Response to event $~ 2$ minutes after reduction in excess air with $\mathrm{CO}$ reported value of $\sim 150 \mathrm{ppm}$

- Crossover section mounted solid state sensor 1 (Zirc1): Response to event $\sim 2$ minutes after reduction in excess air with $C O$ reported value of $\sim 200 \mathrm{ppm}$

- Crossover section mounted solid state sensor 1 (Zirc1): Response to event 2 minutes after reduction in excess air as with $\mathrm{CO}$ reported value of NONE

\section{Conclusions from Testing of TDL CO Analyzer}

The TDL CO analyzer met all performance goals for the project:

- Sub ppm sensitivity to CO 
- Ability to measure at high gas temperature (prior to CO afterburning)

- Ability to maintain alignment and measurement during furnace start up, decoke, normal and abnormal operations

- Ability to detect $\mathrm{CO}$ breakthrough before the furnace exceeded safety, environmental or efficiency limits, vast improvement over existing technology

As with the $\mathrm{O}_{2}$ TDL, the CO TDL provides a path average measurement. This ability can result in a loss of spatial information unlike that provided with point source measurements (CO or combustible sensors). However, for the $\mathrm{CO}$ measurement a path-average is a significant advantage, as shown in Figure and Table 3.

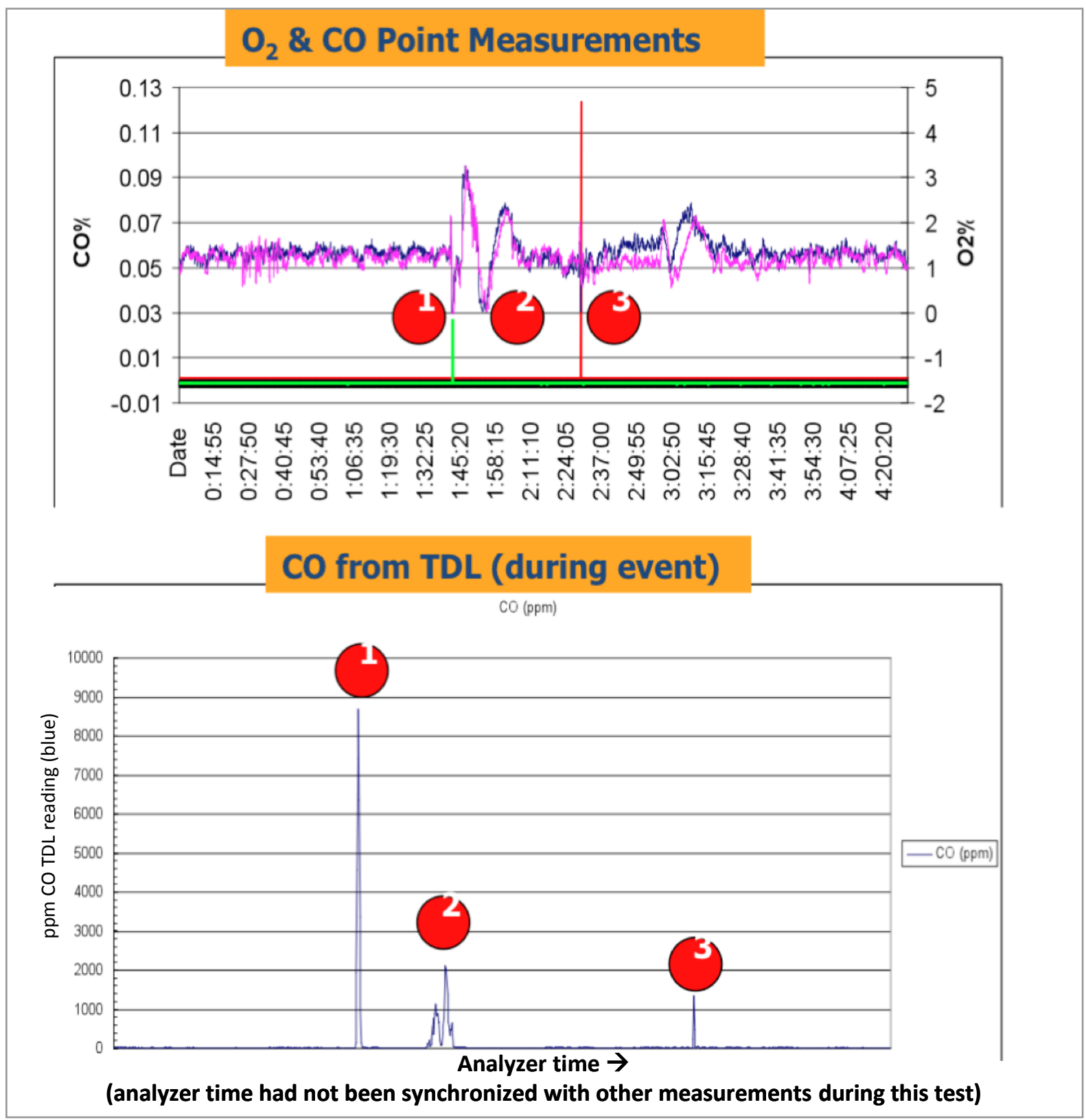

Figure 15. Comparison of TDL Path CO Measurement with Sensor Based Point CO Measurement During Low Excess $\mathrm{O}_{2}$ Excursions 


\begin{tabular}{|c|c|c|}
\hline $\begin{array}{c}\text { O2 reading } \\
\text { (Sensor 1/2) }\end{array}$ & $\begin{array}{c}\text { TDL } \\
\text { Co reading }\end{array}$ & $\begin{array}{c}\text { Co Sensor } \\
\text { reading } \\
\text { (Sensor 1/2) }\end{array}$ \\
\hline \begin{tabular}{c|c}
$0 \% / 0 \%$ \\
$0 \% / 0 \%$
\end{tabular} & $8700 \mathrm{ppm}$ & $0 / 267 \mathrm{ppm}$ \\
\hline & $2017 \mathrm{ppm}$ & $0 / 0 \mathrm{ppm}$ \\
\hline
\end{tabular}

Table 3. Comparison of TDL Path CO Measurement with Sensor Based Point CO Measurement During Low Excess $\mathrm{O}_{2}$ Excursions

Table 3 shows the readings from 2-point oxygen sensors with built in "CO" sensors. These sensors were mounted approximately on either side of the furnace $\sim 1 / 3$ of the firebox towards center. The sensors were installed less than 10' above the TDL CO analyzer with similar gas temperature levels. The point sensors are compared to one TDL CO analyzer that measured across the firebox. During this period there were 3 low oxygen excursions:

\section{Excursion 1:}

- Both oxygen sensors read $\underline{0 \% \mathrm{O}_{2}}$

- TDL CO analyzer measured 8700ppm

- One CO sensor read 0ppm

- Second CO sensor read 267ppm

\section{Excursion 2:}

- Both oxygen sensors read $\underline{0 \% \mathrm{O}_{2}}$

- TDL CO analyzer measured 2017ppm

- One CO sensor read Oppm

- Second CO sensor read Oppm

\section{Excursion 3:}

- One oxygen sensor read $0 \% \mathrm{O}_{2}$, the second read $\underline{0.6 \% \mathrm{O}_{2}}$

- TDL CO analyzer measured 1345ppm

- One CO sensor read 1236ppm

- Second CO sensor read Oppm

The CO point sensors were fully operational, they had been challenged with validation gas before and after this event. The inability to capture the $\mathrm{CO}$ excursions results from a placement issue, not a performance issue. The point sensors will only measure a small sample of the furnace effluent, if they are not in a gradient zone that corresponds to the burner(s) producing $\mathrm{CO}$, there will be no indication of fuel rich combustion.

The TDL CO path sensor measures a much larger cross section of the furnace effluent gas. This combined with the high sensitivity provides an increased probability of sensing a CO breakthrough, enabling reliable safety and control reactions.

\section{Testing of NO TDL Analyzer}

The next approach was to design and install a TDL analyzer to measure Nitric Oxide (NO). Based HITRAN / HITEMP spectra we selected the NO absorption peak located at $1789.4 \mathrm{~nm}$, because the peak is in the valley of two $\mathrm{H}_{2} \mathrm{O}$ absorption peaks, see Figure 16. A $15 \%$ concentration of $\mathrm{H}_{2} \mathrm{O}$ was used in the simulation since this is a median value for combustion processes. 


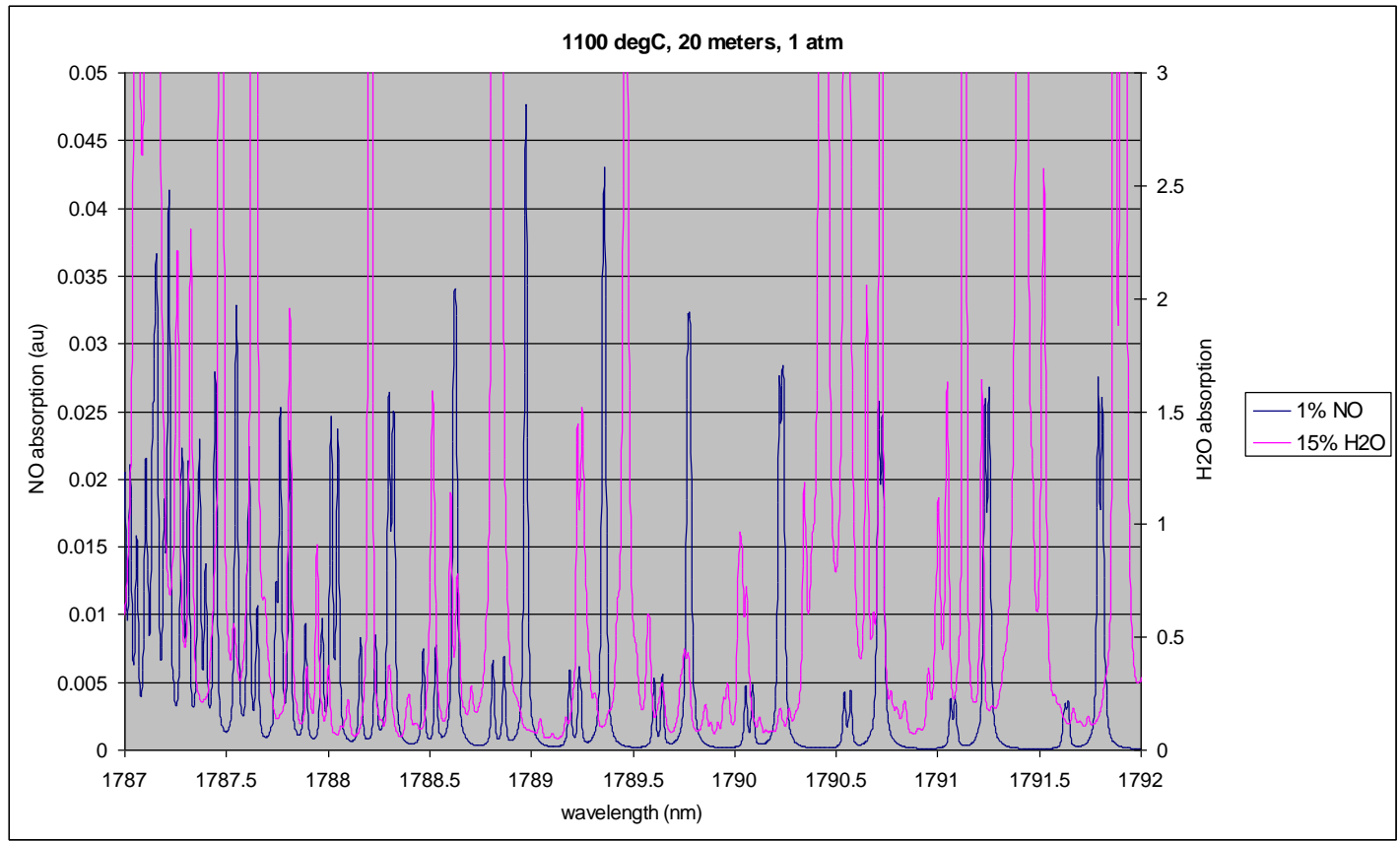

Figure 16. HITRAN Spectra of $\mathrm{NO}$ and $\mathrm{H}_{2} \mathrm{O}$ at Combustion Conditions

The NO TDL analyzer was installed on the ethylene furnace, and a detailed spectral survey was conducted. The spectra approximately match the HITRAN/HITEMP $\mathrm{H}_{2} \mathrm{O}$ absorption, however the $\mathrm{H}_{2} \mathrm{O}$ absorption is much larger than predicted by HITRAN/HITEMP in this wavelength range, with many saturation spots. Unfortunately, the $\mathrm{H}_{2} \mathrm{O}$ peaks near $1789.4 \mathrm{~nm}$ saturated, making this $\mathrm{NO}$ peak unsuitable for measurement. The best peak found during the online field spectral survey is at 1790.2 $\mathrm{nm}$ (Figure 17).

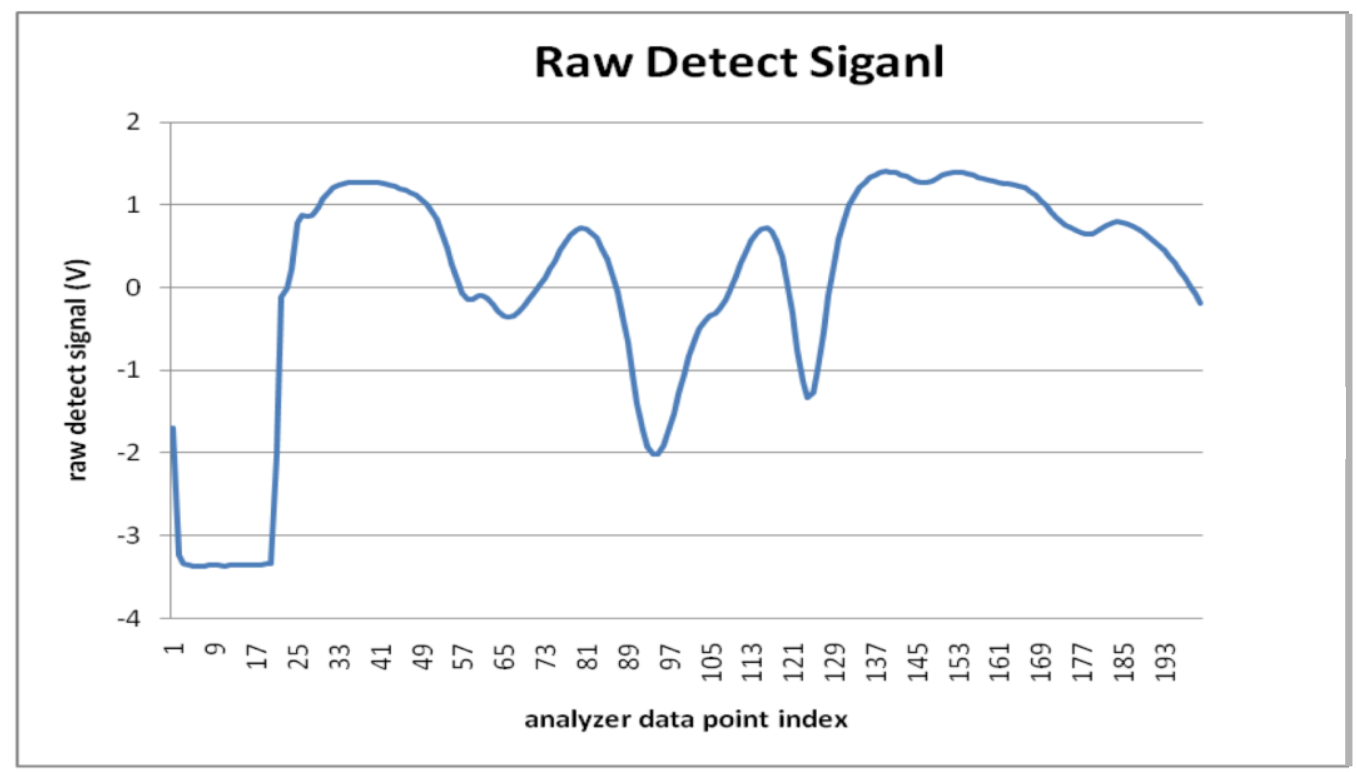

The absorption features are all from $\mathrm{H} 2 \mathrm{O}$. NO absorption is too small to be visually identified. Xaxis is the analyzer data point index.

Figure 17. Field Spectra from Survey at 1790.2nm, Absorption Peaks are from $\mathrm{NO}$ and $\mathrm{H}_{2} \mathrm{O}$ 
Next, NO gas standard was put in the serial validation cell of the TDL analyzer. This validation gas "spiked" the NO concentration being measured by the TDL analyzer. The process gas may contain NO, by spiking NO into the laser beam we are able to compare the process data with process data + a known concentration of NO. By subtracting "spiked" absorbance - "process" absorbance", as illustrated in Figure 18 , the possibility of NO measurement can be evaluated.

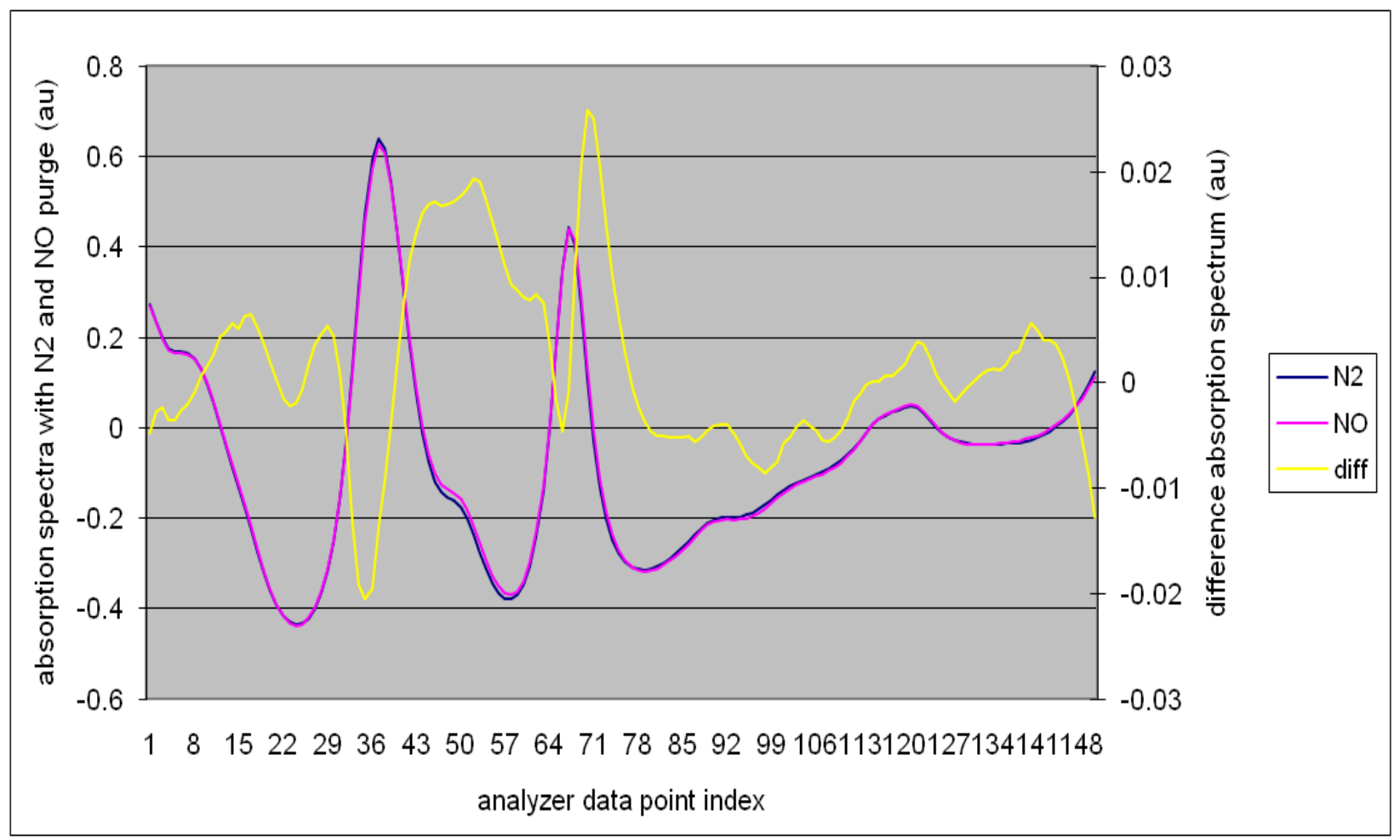

Figure 18.Comparison of Process Spectra over a spectral range of approximately $1790.1 \mathrm{~nm}$ to $1790.4 \mathrm{~nm}$. It was difficult to specify the true wavelength range because the actual $\mathrm{H} 2 \mathrm{O}$ absorption at furnace temperatures doesn't correspond directly to Hitran database (moisture).

By analyzing the differential spectra, it was obvious that the adjacent $\mathrm{H} 2 \mathrm{O}$ peaks are too large for an accurate and sensitive NO measurement. The absorbance of NO in the validation cell is less than 0.003 au. The analyzer was left online with high automatic spectra capture rate to see any big NO process event.

\section{Departure from Planned Methodology}

Having found that TDL based measurement of NO was not possible in this process, we then evaluated the future possibility of modeling the NO concentration in the process.

In Figure a comparison of Excess $\mathrm{O}_{2}$ TDL reading versus CEMS NOx reading is shown. There is very strong correlation between Excess $\mathrm{O}_{2}$ TDL reading and CEMS NOx reading. The obvious difference in the data is the time offset. Since the CEMS NOx analyzer is located at the stack, it is estimated to have $>$ a 2 minute delay when compared to the events occuring in the combustion section.

Future efforts for this project may include modeling of the NOx in the combustion zone using TDL $\mathrm{O}_{2}$ readings as a primary model input. 


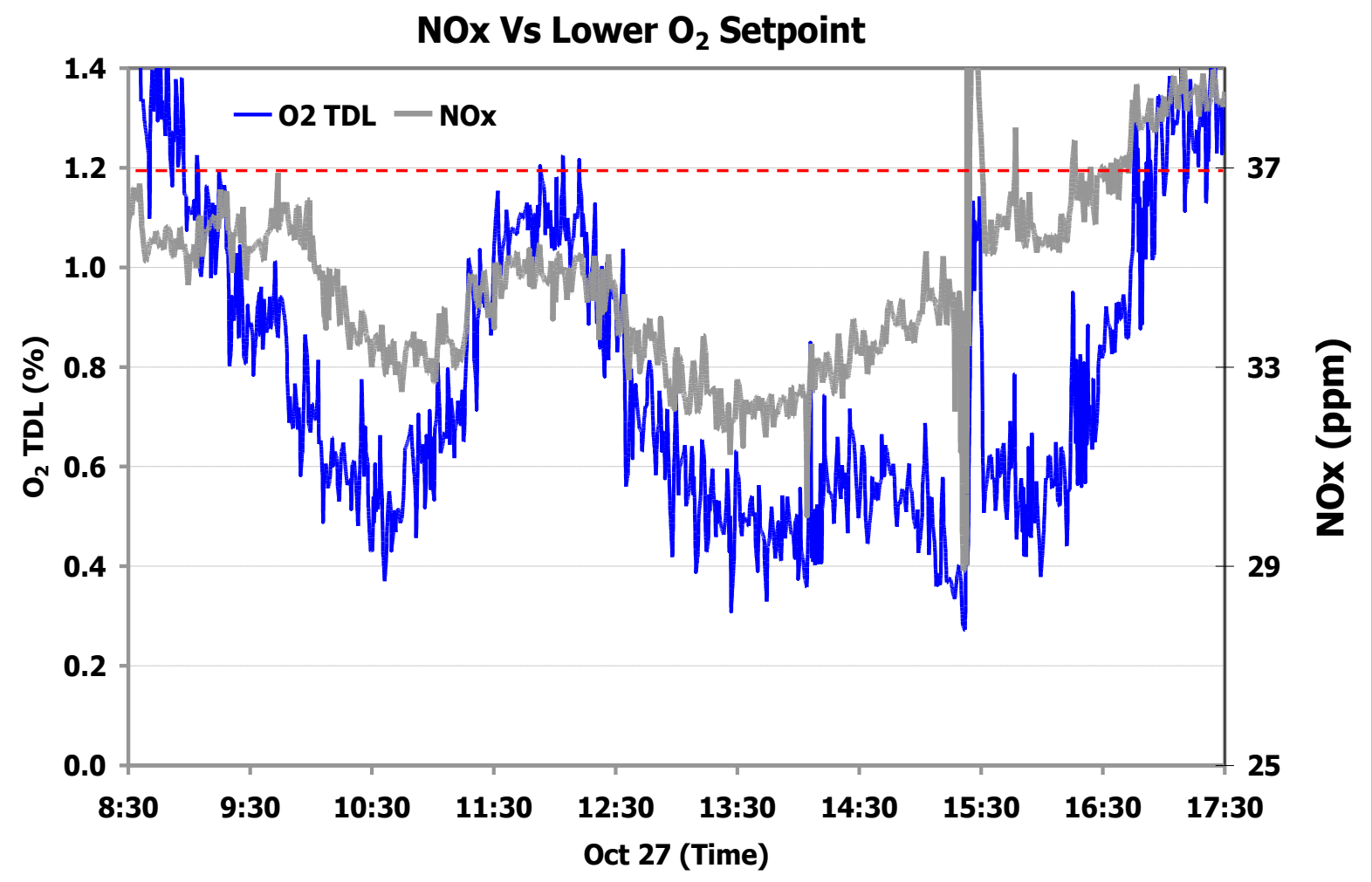

Figure 19. Comparison of Excess $\mathrm{O}_{2}$ TDL Reading versus CEMS NOx Reading

\section{Conclusions from Testing of TDL NO Analyzer}

TDL NO measurement in the combustion region is not possible. The $\mathrm{H}_{2} \mathrm{O}$ absorption is so big in this wavelength range that we can only select limited NO peaks for the measurement. The best is at 1790.2 $\mathrm{nm}$. The large $\mathrm{H}_{2} \mathrm{O}$ interference results in an $\mathrm{NO}$ detection limit of $>1 \%$ under process conditions. This is not acceptable for process control. There is a future possibility to model the NO concentration using the $\mathrm{TDL} \mathrm{O}_{2}$ reading as a primary model input.

\section{Problems Encountered and Proven or Proposed Solutions for Combustion Zone Analysis} In general the $\mathrm{O}_{2}$ and CO TDL measurements were very successful. Development and testing was completed with all performance goals met. TDL NO measurement was not possible under process conditions. The main problems encountered and solutions are shown below.

Table 4. Problems Encountered and Corresponding Solutions

Problems Encountered

Solutions Found or Proposed

\section{Measurement reliability}

Alignment during all phases of furnace operation

Improved design for on furnace mounting of TDL analyzers. Diverging beam optics with large detector window/focusing lens

Nitrogen or instrument air purge in front of the

Survivability when measuring in high temperature processes process window to prevent heat conduction into the TDL electronics 


\begin{tabular}{|l|l|}
$\begin{array}{l}\mathrm{H}_{2} \mathrm{O} \text { interference for } \mathrm{O} 2 \text { measurement at high } \\
\text { temperature }\end{array}$ & $\begin{array}{l}\text { Spectral survey to determine optimum absorption } \\
\text { line selection. Baseline treatment algorithms to } \\
\text { minimize effects of spectral overlap }\end{array}$ \\
\hline $\begin{array}{l}\mathrm{H}_{2} \mathrm{O} \text { interference for } \mathrm{CO} \text { measurement at high } \\
\text { temperature }\end{array}$ & $\begin{array}{l}\text { Spectral survey to determine optimum absorption } \\
\text { line selection. Baseline treatment algorithms to } \\
\text { minimize effects of spectral overlap }\end{array}$ \\
\hline $\begin{array}{l}\mathrm{H}_{2} \mathrm{O} \text { interference for NO measurement at high } \\
\text { temperature }\end{array}$ & $\begin{array}{l}\text { No direct solution found. Possibility of future } \\
\text { modeling of NOx in combustion zone using TDL O2 } \\
\text { as a primary model input }\end{array}$ \\
\hline
\end{tabular}

\section{Departures from Planned Methodology and Impact}

The most significant departure from the planned methodology is the inability to measure NO in combustion conditions using TDL analyzers. The impact is slight since the primary inputs for control of safety, efficiency and emissions are $\mathrm{O}_{2}$ and CO. However, at times a furnace operation may be limited due to NOx emissions restrictions in NOx attainment regions of the US. If after implementation of the improved furnace control scheme, NOx measurement is shown to be a constraint we will investigate the possibility of modeling the NOx in the combustion zone.

The second significant departure from the planned methodology was the realization that multiple measurement paths in the burner zone were not required or desired. The CFD modeling and subsequent testing proved that a single path measurement in the furnace crossover section is optimum. The impact on the project is insignificant. In fact the ability to representatively measure using one path ultimately reduces the cost and complexity of the analytical system.

The ultimate installation cost goal is currently higher than the project goal. Dow's estimate for installed cost for an $\mathrm{O}_{2} / \mathrm{CO}$ based TDL analysis system on the largest of our ethylene furnaces is $\$ 136,200$ ( $\$ 75,000$ of this is for the $\mathrm{O}_{2} / \mathrm{CO}$ TDL analyzers). Dow is currently working with Yokogawa (commercial supplier) to reduce this cost. Ultimately we expect the installed cost to reduce in the region of $\$ 110$ 120,000 USD. The cost reduction will come from supplier analyzer reduction plus installation and commissioning reduction. We expect little effect from this deviation in the installed cost goal. The current $\mathrm{ROI}$ estimations for installation of $\mathrm{O}_{2} / \mathrm{CO}$ TDL analyzers is $<4$ months, this is acceptable for the chemical and refining industries.

\section{Rapid BTU Measurements of Fuel}

\section{Goal}

The project object is to develop a rapid BTU measurement to enable feed-forward control of fuel and coil outlet temperature (COT), thereby reducing the variability in COT and other control set points for ethylene furnace.

During this project Dow conducted investigations on several technologies applicable for rapid BTU measurements. Several commercial techniques were evaluated and the potential advantages and disadvantages was explored. The technologies evaluated were:

- Gas Chromatography

Advantage-Familiar, Robust, Multi-Component

Disadvantage-Slow Response-Time

- Multi-wavelength Spectroscopy

Advantage-Fast Response-time, Low LTCO vs GC

Disadvantage-Expensive/complicate for complete compositional analysis

- Raman Spectroscopy

Advantage-Fast Response-time

Disadvantage-Expensive, high LTCO 
- Specific Gravity

Advantage-Simple SHS, Inexpensive

Disadvantage-Large Error with components interferences

- Oxygen Demand

Advantage-Direct BTU measurement

Disadvantage-Expensive vs Specific Gravity

Many of these technologies are too slow, high installed cost, inaccurate, and/or unreliable. The few which shown promise in meeting the needs of the application target (rapid analysis of fuel gas for an ethylene cracker): Multi-wavelength spectroscopy, Oxygen Demand, and Specific Gravity. In Phase I of the project Dow evaluated and conducted laboratory analyzer performance validation on each of the technologies and determined the optimal system for the on-line field trial at Dow's ethylene furnace.

Table 5. Comparison of Actual Accomplishments with Project's Goals/Objectives

\begin{tabular}{|c|c|c|}
\hline Task & Goal & Actual Accomplishment \\
\hline \multicolumn{3}{|c|}{ Offline Measurement Development } \\
\hline Multi-wavelength NIR & $\begin{array}{l}\text { - Measurement speed }<20 \text { seconds. } \\
\text { - Measurement availability }>95 \% \\
\text { - Suitable for a wide range of fuels }\end{array}$ & $\begin{array}{l}\text { - Tech met performance specification } \\
\text { - Long-term reliability and drift did not } \\
\text { meet field performance specifications } \\
\text { - Met ethylene furnace's limited fuel gas } \\
\text { range of specifications }\end{array}$ \\
\hline Specific Gravity & $\begin{array}{l}\text { - Measurement speed }<20 \text { seconds. } \\
\text { - Measurement availability }>95 \% \\
\text { - Suitable for a wide range of fuels }\end{array}$ & $\begin{array}{l}\text { - Tech met performance specification } \\
\text { - Long-term reliability and drift did meet } \\
\text { field performance specifications } \\
\text { - Met ethylene furnace's fuel limited gas } \\
\text { range of specifications }\end{array}$ \\
\hline Oxygen Demand & $\begin{array}{l}\text { - Measurement speed }<20 \text { seconds. } \\
\text { - Measurement availability }>95 \% \\
\text { - Suitable for a wide range of fuels }\end{array}$ & $\begin{array}{l}\text { - Tech met performance specification } \\
\text { - Long-term reliability and drift did meet } \\
\text { field performance specifications } \\
\text { - Met ethylene furnace's fuel gas range of } \\
\text { specifications }\end{array}$ \\
\hline \multicolumn{3}{|c|}{ Ethylene Furnace On-line Field Testing } \\
\hline Multi-wavelength NIR & $\begin{array}{l}\text { - Field testing under forced process } \\
\text { changes }\end{array}$ & $\begin{array}{l}\text { - Task not required due to technology's } \\
\text { long-term reliability and drift performance } \\
\text { specifications didn't meet application's } \\
\text { needs }\end{array}$ \\
\hline Specific Gravity & $\begin{array}{l}\text { - Field testing under forced process } \\
\text { changes }\end{array}$ & - Completed as proposed \\
\hline Oxygen Demand & $\begin{array}{l}\text { - Field testing under forced process } \\
\text { changes }\end{array}$ & - Completed as proposed \\
\hline
\end{tabular}




\section{Summarize Project Activities}

\section{Original Hypothesis}

An important control variable for controlling a furnace is the amount of fuel distributed to burners. The amount of fuel delivered is set according to the desired firing duty (to achieve the target COT) and the fuel's BTU value. Therefore, a rapid fuel gas BTU analysis is a critical parameter in proper furnace control, feed forward control.

Unanticipated in fuel composition changes lead to inefficient furnace performance: 1) Change in fuel composition can change the fuel's BTU value resulting in deviation from the desired cracking patterns lead to economic loss due to non-optimized product distribution. 2) Change composition can change the required oxygen for combustion, thus less $\mathrm{O}_{2}$ is present for combustion resulting in less efficiency causing fuel to be wasted.

Best practice in the industry to measure BTU value of fuels relies on Gas Chromatography (GC). While this technology is proven and can be made reliable, it has a slow response time (often times several minutes or more). And fuel flow is usually controlled in a feedback loop in concert with COT, not feedtoward loop. Thus, a rapid BTU measurement can enable feed-forward control of fuel and COT, thereby reducing the variability in COT and other set points for a cracker.

Dow evaluated and conducted laboratory testing of three commercial technologies to validate their measurement performance specifications for on-line field trial in a ethylene cracker. The three commercial available analyzer systems were 1) Axsun multi-wavelength filter NIR, 2) Hobre oxygen demand analyzer, and 3) Solatron specific gravity analyzer.

\section{Multi-wavelength Filter NIR}

\section{Approaches Used}

The packaged Axsun NIR Micro Spectrometer is shown in Figure. The spectrometer included a broadband semiconductor laser light source, MEM (micro-electromechanical) tunable optical filters, and detector. Light was coupled to and from the probe or sample cell with fiber optics. It was configured for general purpose area environmental safety classification with the dimensions of $8.3 \times 5.5 \times 4.0$ inches and weighs $3.1 \mathrm{lbs}^{1}$.

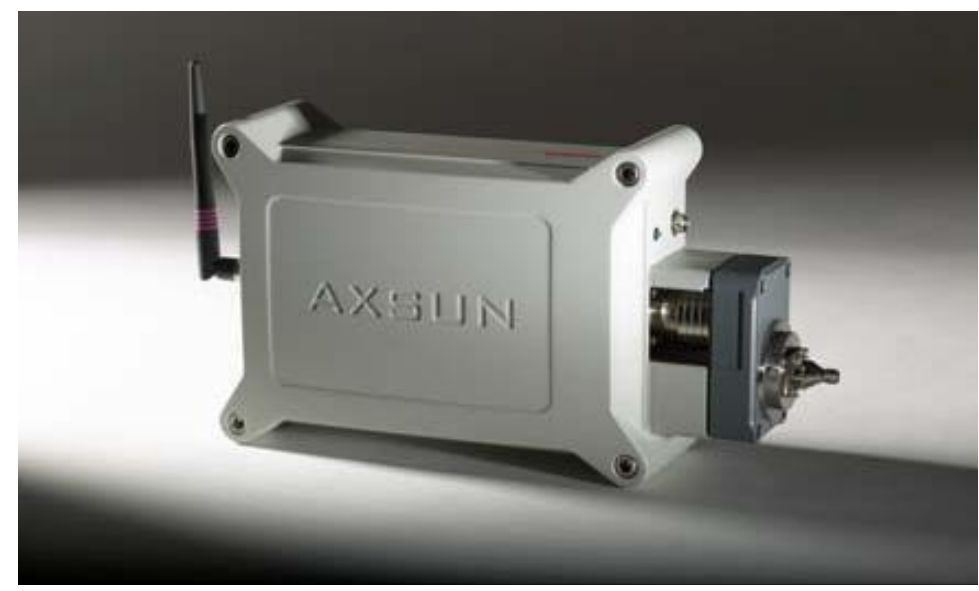

Figure 20. A picture of the Axsun NIR IntegraSpec Micro Spectrometer

There are 3 laser light sources which can be used to build the spectral coverage. The first, from 1350$1550 \mathrm{~nm}$, covers the $\mathrm{OH}$ and $\mathrm{NH} 1^{\text {st }}$ overtone region. The second, from 1550-1800 nm, covers the region where the $1^{\text {st }}$ overtones of $\mathrm{CH}$ stretches are located. The third laser ranges from 1800-1970 nm and sees the $\mathrm{CO}$ and $\mathrm{OH}$ combination bands.

${ }^{1}$ www.axsun.com/media/pdfs/pittcon2005 tunable sources poster.pdf 
Analyzer performs well in a laboratory setting is not sufficient to conclude that it will perform as well in the field where the spectrometer is located in harsh environments with only moderate climate control or protection from the weather. Therefore, ambient temperature ramp trials were performed along with drift at room temperature. The results were compared with the those generally observed in the standard FTNIR spectrometers.

Three types of experiments were conducted; 1) constant temperature conditions, 2) temperature ramp went from room temperature to $\sim 120^{\circ} \mathrm{F}$ to $\sim 10^{\circ} \mathrm{F}$ back to room temperature, and 3) room temperature test with various hydrocarbons introduced to the sample cell. The following gases were used in the gas tests:

1. $2.5 \%$ Methane $\left(\mathrm{CH}_{4}\right)$ in Nitrogen

2. $20 \%$ Ethane $\left(\mathrm{C}_{2} \mathrm{H}_{6}\right)$ in Nitrogen

3. $10 \%$ Propane $\left(\mathrm{C}_{3} \mathrm{H}_{8}\right)$ in Nitrogen

4. $10 \%$ Propylene $\left(\mathrm{C}_{3} \mathrm{H}_{6}\right)$ in Nitrogen

Rather than looking at absorbance spectra "snapshots" it is informative to look at the drift, or the maximum minus the minimum absorption values over the experiment, as summarized in Table 6 . .

\begin{tabular}{|l|c|c|}
\hline \multicolumn{1}{|c|}{ Wavelength Range } & $\mathbf{1 3 5 0 - 1 5 4 0 \mathbf { n m }}$ & $\mathbf{1 5 4 0 - 1 8 0 0 \mathbf { n m }}$ \\
\hline Axsun-Constant Temp. & $0.5 \pm 0.2 \mathrm{mAU}$ & $0.5 \pm 0.1 \mathrm{mAU}$ \\
\hline Axsun-Temp Ramp & $8 \pm 5 \mathrm{mAU}$ & $9 \pm 2 \mathrm{mAU}$ \\
\hline
\end{tabular}

Table 6. Maximum-Minimum Absorbance for Configurations in Separate Experiments Categorized by Laser Module Wavelengths and Presented in mAU.

Another method of quantifying drift is to look at the standard deviations of the absorbance values of a spectrum over the course of the experiment, as illustrated in B)

Figure .

One way to more closely simulate performance under "real" process conditions is to heat only the cell, not the analyzer. The cell was heated from $30 \mathrm{C}$ to $401 \mathrm{C}$ and absorbance spectra were collected at 9 different temperatures throughout that range. B)

Figure displays the absorption spectra (Part A) and the standard deviations from heating only the cell. 


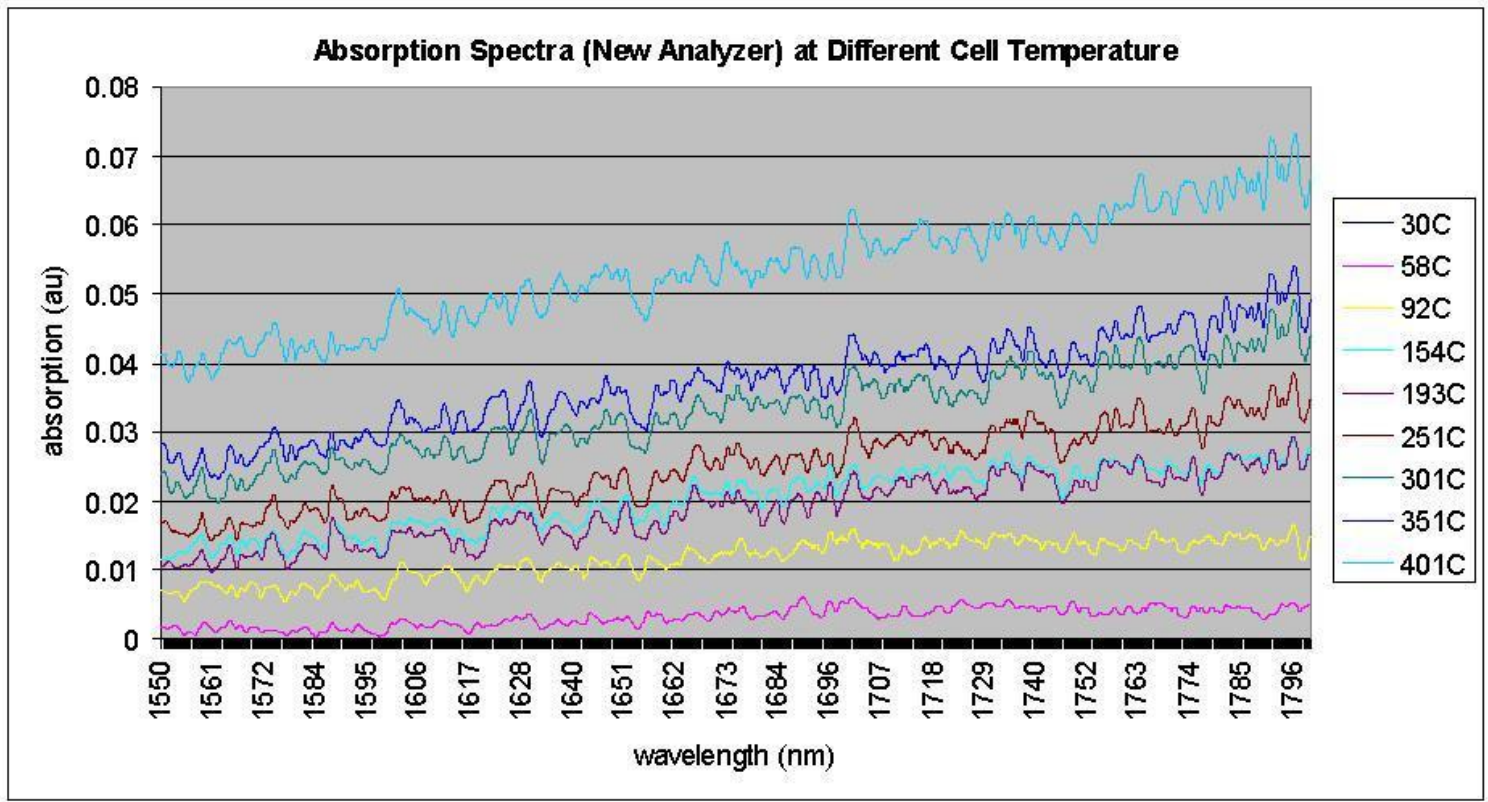

A)

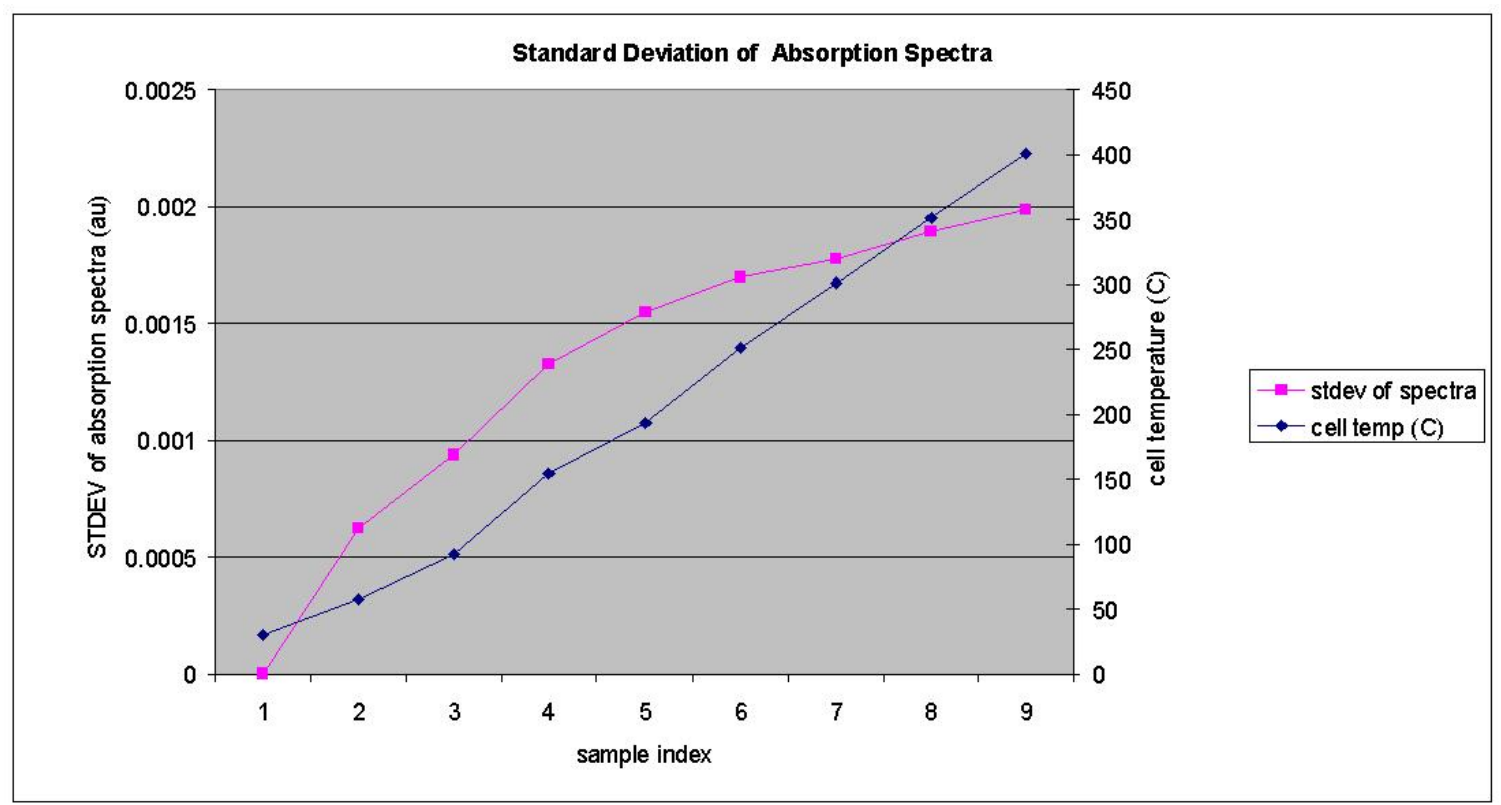

B)

Figure 21. Axsun Bench and Selectively Heating Sample cell. A) Absorbance Spectra. B) Standard Deviations of Absorbance.

The last performance evaluation was conducted using a model to quantify hydrocarbons present (methane, ethane, propane and propylene). The model performances achieved by the analyzer are summarized in Table 7. The predictive capability of Axsun bench is comparable to other common near infrared technologies. 


\begin{tabular}{|c|c|c|c|}
\hline Parameter & Maximum Residual (au) & Absolute Error & Relative Error \\
\hline $2.5 \% \mathrm{CH} 4$ & 0.0022 & $0.06 \%$ & $2.2 \%$ \\
\hline $20 \% \mathrm{C} 2 \mathrm{H} 6$ & 0.0017 & $0.11 \%$ & $0.5 \%$ \\
\hline $10 \% \mathrm{C} 3 \mathrm{H} 8$ & 0.0033 & 0.17 & $1.7 \%$ \\
\hline $10 \% \mathrm{C} 3 \mathrm{H} 6$ & 0.0013 & $0.05 \%$ & $0.5 \%$ \\
\hline
\end{tabular}

Table 7. Model Results

\section{Conclusion from Multi-wavelength Filter NIR}

The performance of the AXSUN bench is similar to other NIR spectroscopic technologies in terms of drift and spectral noise. Moreover, spectrometer packaging is not rated for Class 1 Division 2 for safety and environmental area classification as required by the majority of process analytical applications. Therefore, at current time the advantages offered by the Filter NIR technology are not compelling enough to purse further development and field testing for furnace fuel BTU application.

\section{$\underline{\text { Specific Gravity Analyzer }}$}

\section{Approaches Used}

The natural gas production and distribution industry uses a variety of techniques to estimate or determine natural gas heating value. One correlative technique used by the natural gas industry takes advantage of the near linear relationship between heating value and relative density. The American Gas Association's, AGA, transmission measurement committee report no. 5 is a frequently cited reference for this technique ${ }^{2}$. Carbon monoxide, carbon dioxide and nitrogen are probable natural gas components that can introduce error when correlating gas relative density to heating value. AGA report no. 5 attempts to minimize these potential errors through the use of "correction factors" that assume constant concentrations of $\mathrm{CO}, \mathrm{CO}_{2}$ and/or $\mathrm{N}_{2}$. Figure illustrates the relationship between net heating value and relative density for selected gases.

\footnotetext{
2 “Fuel Gas Energy Metering: Transmission Measurement Committee Report No 5" American Gas Association, Cat \# XQ0776 (1996).
} 


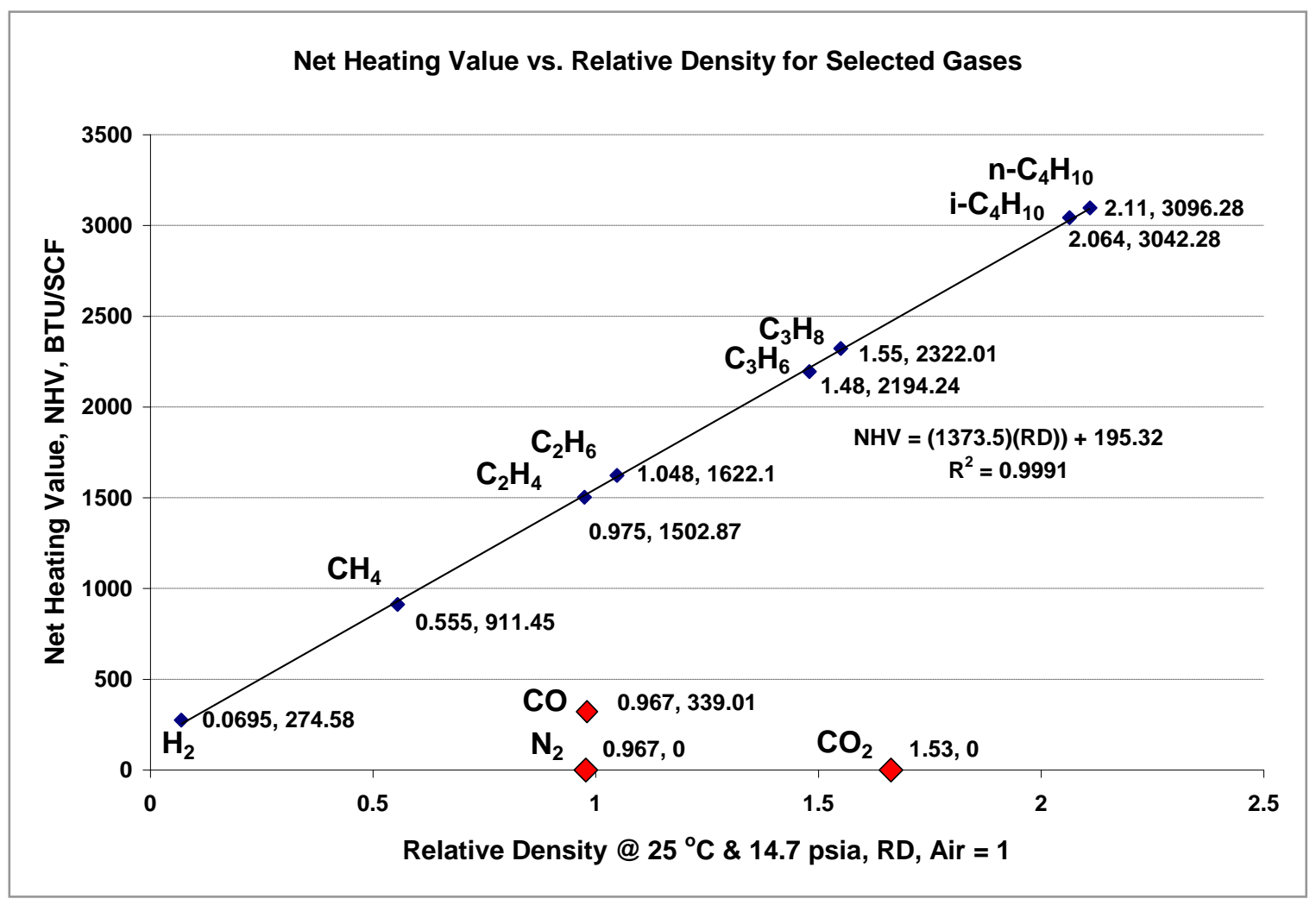

Figure 22. Net Heating Value versus Relative Density for Selected Gases

Estimation of fuel gas net heating value from relative density is an attractive measurement option for Dow's ethylene furnaces. Field testing has to be planned to determine the accuracy and precision of ethylene furnace fuel gas energy content estimates based on relative density measurements. Should fuel gas energy content can be estimated with the accuracy and precision required for a value added ethylene furnace control scheme would receive the following benefits:

- Low cost of ownership

- Total installed cost is estimated at $\approx \$ 50-60 \mathrm{M}$ (2006 dollars)

- Low utility requirements

- Low maintenance intensity

- Rapid response time

- T90 response time $\leq 10$ seconds

The Emerson Solartron model 3098 gas specific gravity (relative density) transducer has been selected for the planned tests, as shown in Figure. The decision to select the Solartron 3098 was heavily influenced by its superior accuracy and precision specifications and its $25+$ year proven track record. Examination of Figure shows that the relative density relationship to net heating value is $7.3 \times 10^{-4}$ $(\mathrm{BTU} / \mathrm{SCF})^{-1}$. The Solartron 3098 delivers specific gravity measurement precision of $+/-0.02 \%$ of reading. An ethylene furnace fuel gas with a specific gravity of 0.30000 would potentially be determined to $+/-6 \times 10^{-5}$ with the Solartron 3098, thus, providing a good opportunity to accurately estimate the fuel gas net heating value. 


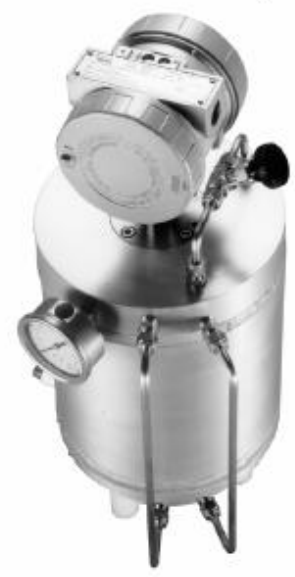

Figure 23. Emerson Solartron 3098 Specific Gravity Fuel Gas Analyzer

On-line gas chromatographic data for Dow Freeport furnace fuel gas (illustrated in Figure ) were used to determine the relationship between furnace fuel gas net heating value and relative density. Data plotted in Figure were acquired by calculating fuel gas net heating value and relative density from the gas chromatograph's analyses of $\mathrm{H}_{2}, \mathrm{~N}_{2}, \mathrm{CH}_{4}, \mathrm{CO}, \mathrm{CO}_{2}, \mathrm{C}_{2} \mathrm{H}_{4}, \mathrm{C}_{2} \mathrm{H}_{6}, \mathrm{C}_{3} \mathrm{H}_{6}$ and $\mathrm{C}_{3} \mathrm{H}_{8}$ concentrations in Freeport furnace fuel gas.

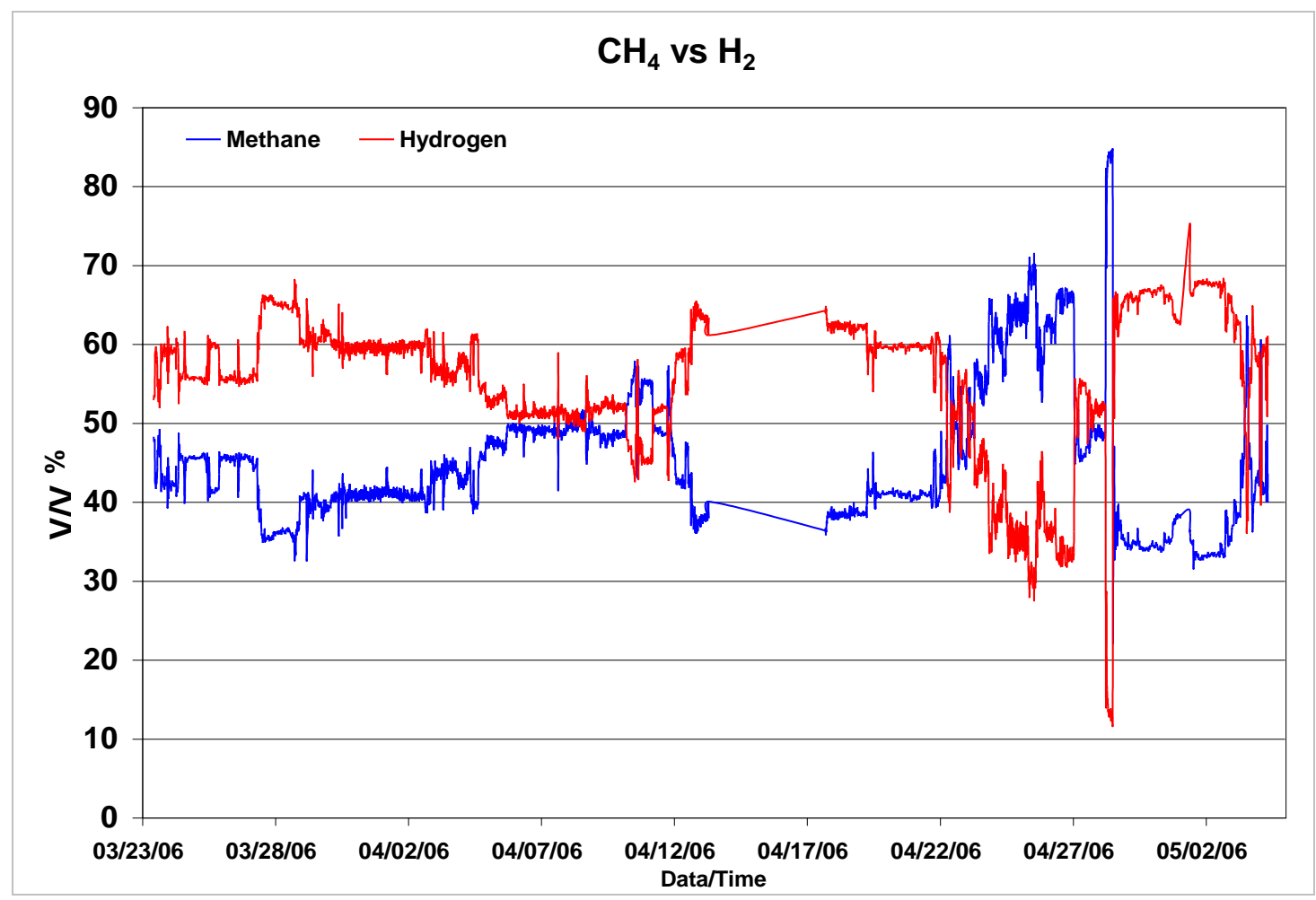

Figure 24. Texas Furnace Average Fuel Gas Composition and Range 


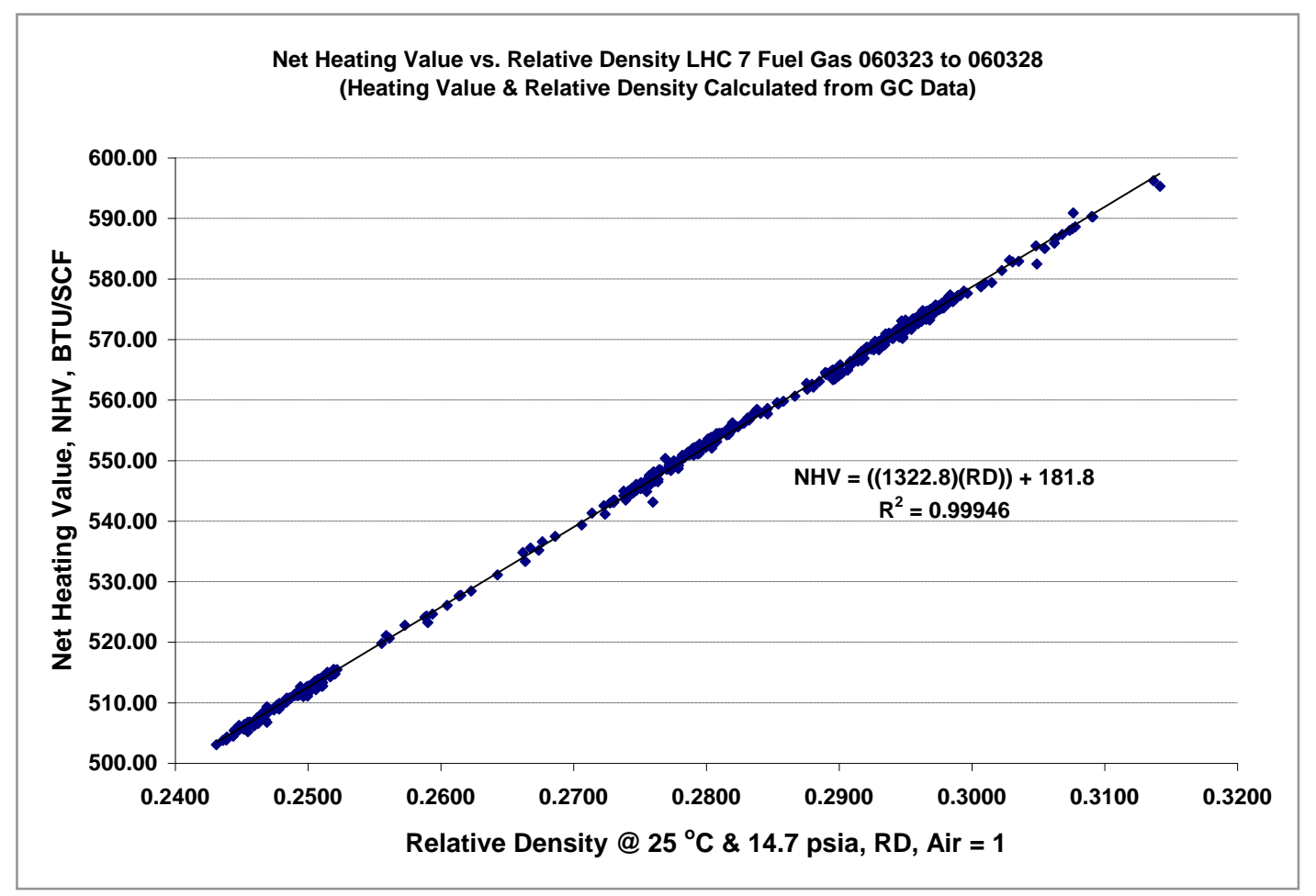

Figure 25. Freeport Furnace Fuel Gas Net Heating Value versus Relative Density

\section{Conclusion from Specific Gravity Analyzer}

Figure 25 indicates a near linear relationship between furnace fuel gas net heating value and relative density indicating that estimation of net heating value from relative density measurements could be a reasonable measurement option. Variations in $\mathrm{CO}, \mathrm{CO}_{2}$, and $\mathrm{N}_{2}$ concentrations introduce errors to the estimation of net heating value as stated previously. However, the Solartron 3098 quantify errors associated with correlation of relative density to fuel gas net heating value for Freeport Furnace's fuel compositions and concentration ranges are within the performance measurement precision for the fuel feed control, as illustrated in Figure 26.

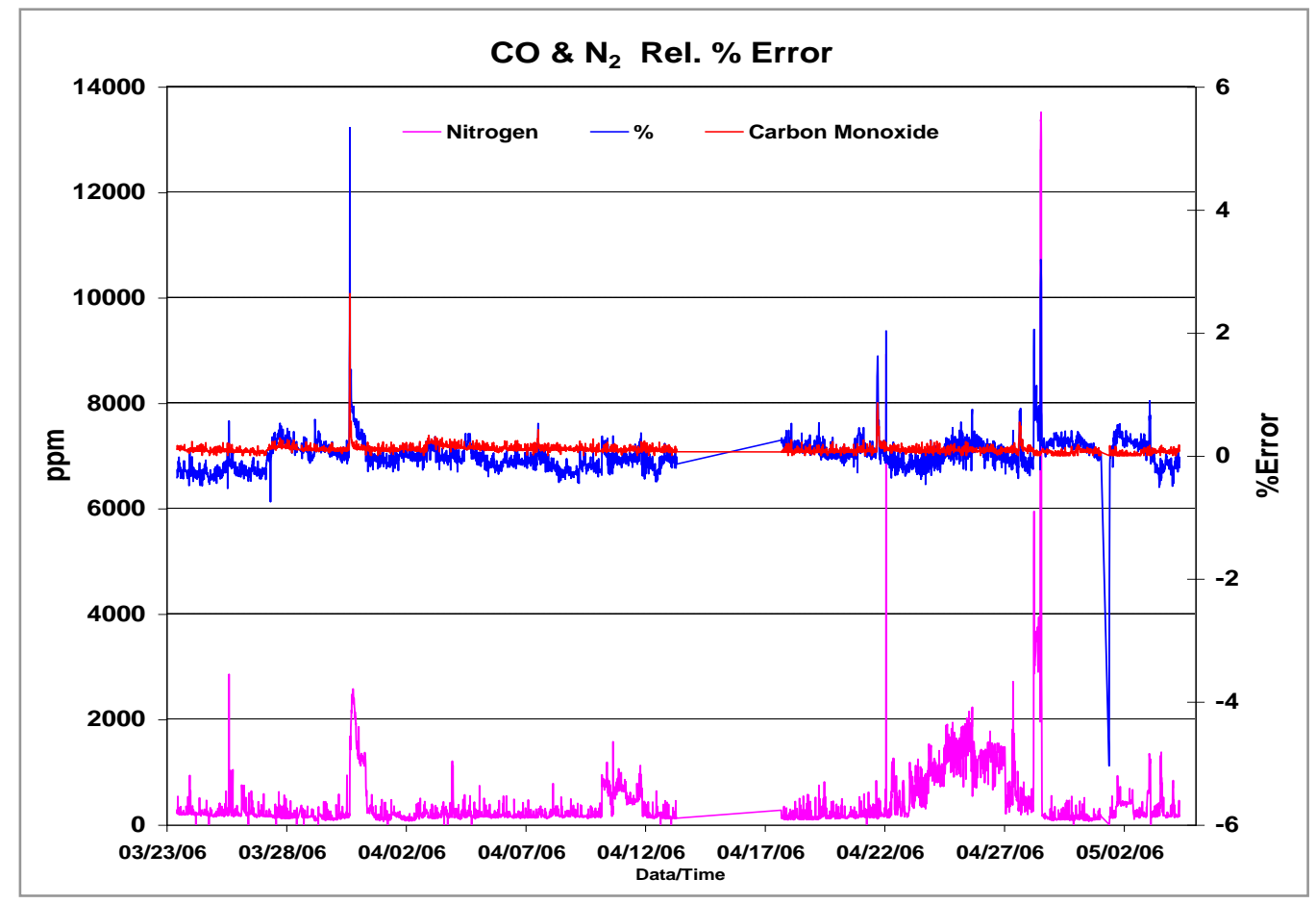


Figure 26. Densitometer Quantitative Relative Error Associated with $\mathrm{CO}$ and $\mathrm{N}_{2}$ in Fuel Composition

Therefore, analyzer was purchased and implemented at the Dow Freeport Olefins furnace to estimate the value of improved ethylene furnace control schemes enabled by the rapid determination of fuel gas energy content.

\section{Oxygen Demand Analyzer}

\section{Approaches Used}

Frequent and sudden changes in the fuel gas composition will immediately lead to the instability operation of the furnace combustion process which can cause inefficient furnace performance and unwanted emissions. Hobre Instruments Wobbe Index analyzer, as shown in Figure , monitoring Calorific value based on residual oxygen measurement could be a potential technology to control the air/fuel ratio that the furnace's COT temperature fluctuations are minimized and combustion process occurs with maximum efficiency.

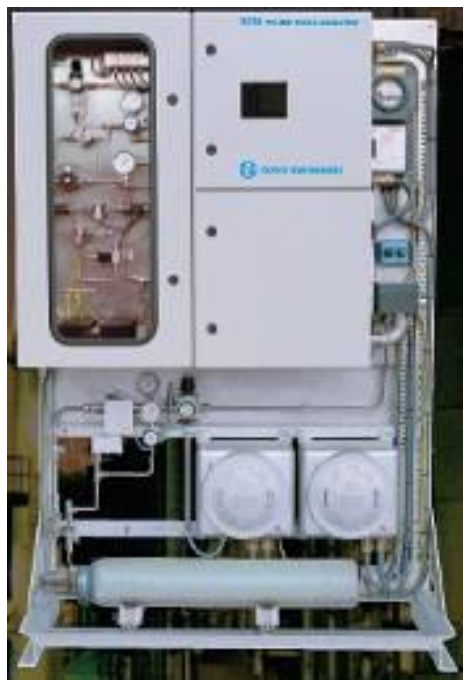

Figure 27. Hobré Instruments Wobbe Index Analyzer 


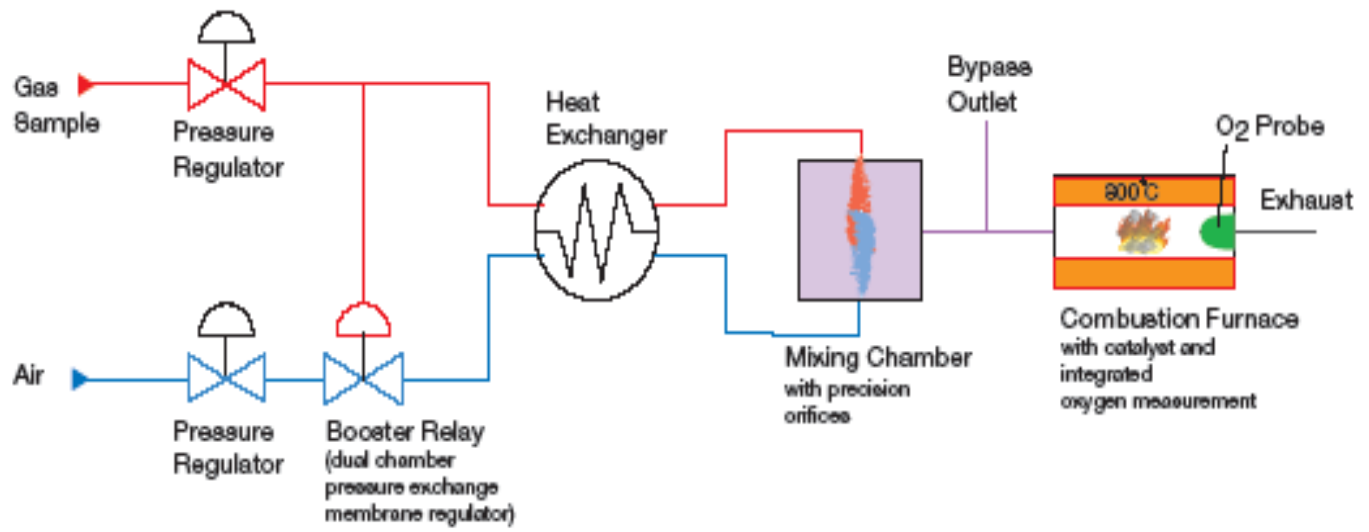

Figure 28. Operational Schematic of an Hobre Wobbe Analyzer

As show in

Figure, the measurement principle of the Hobré Instruments Wobbe Index analyser is based on the measurement of residual oxygen after catalytic combustion of the flare or fuel gas. A small sample flow is mixed continuously with dry air in a constant fixed ratio. This ratio depends on the gas composition and is determined on a case by case basis. Using an electrical heated catalytic oven the air fuel mixture is fully burned at a temperature of approximate $800^{\circ} \mathrm{C}$. The residual oxygen is measured by a highly accurate and reliable zirconia oxide cell. This residual oxygen content provides an accurate measurement of the Combustion Air Requirement and correlates well to the Wobbe Index of the gas. ${ }^{3}$

On-line gas chromatographic data for Dow Freeport furnace fuel gas (illustrated in Figure ) were used to determine the relationship between furnace fuel gas calorific value and relative measurement error. As shown in Figure 29, the measurement accuracy is with $1 \%$ of typical measured value.

${ }^{3}$ http://www.hobre.com/files/products/Wobbe_Index_General_Information_rev.1.pdf 


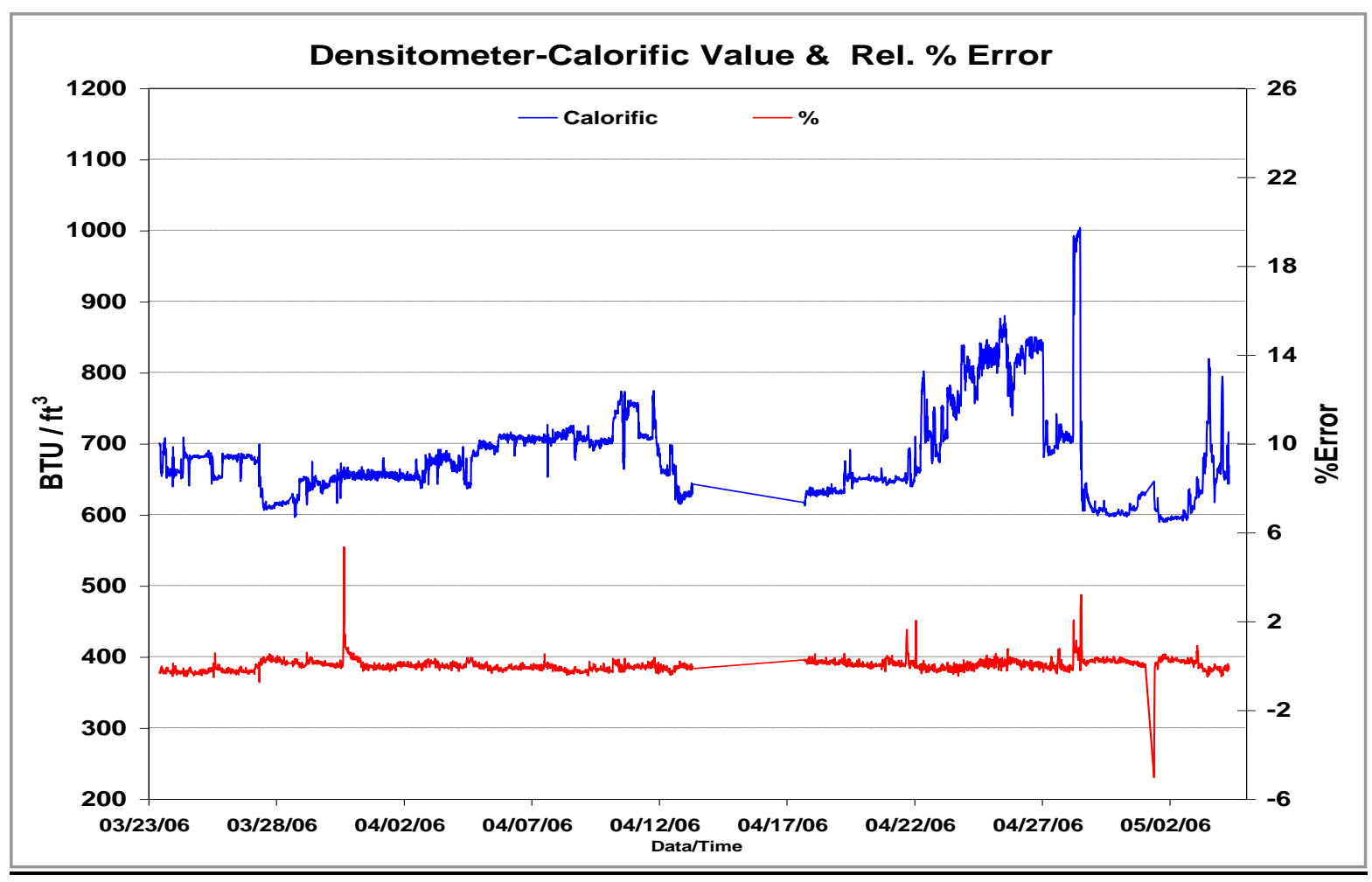

Figure 29. Hobre Wobbe Index Analyzer Calorific Value and Relative Measurement \% Error

\section{Conclusion for Oxygen Demand Analyzer}

Variations in Freeport furnace fuel compositions and $\mathrm{CO}, \mathrm{CO}_{2}$, and $\mathrm{N}_{2}$ concentrations will introduce errors to the fuel calorific value as stated previously. However, the typical $1 \%$ error is lower than the required measurement performance furnace fuel BTU accuracy for furnace control. Therefore, a Hobre Wobbe Index analyzer was purchased and implemented at the Dow Freeport Olefins furnace to estimate the value of improved ethylene furnace control schemes enabled by the rapid determination of fuel gas energy content.

\section{Process Optimization}

The operation and control of a furnace account for a very large fraction of the total energy consumed in producing olefins (e.g., ethylene and vinyl chloride monomer). There have been very few significant improvements made in the design and operation of a modern furnace. Furthermore, many of the furnaces in use today in the petrochemical industry are 20 years old or more. This situation presents a unique challenge to the industry in that if significant improvements in energy consumption are required, the innovations and improvements must be applicable not only to new furnaces having more efficient designs, but they also must be applicable to the large installed base of older, existing furnaces prevalent everywhere. A modern furnace can cost between $\$ 10-15$ million and simply replacing older furnaces with new ones is cost prohibitive, particularly considering there are 10+ furnaces for a modern ethylene cracker. The concepts contained in this project will enable both new and old furnaces to achieve significant energy improvements at a reasonable, justifiable cost to the industry.

The primary control objectives for operating a furnace include (1) Maximizing the value of its products (primarily the severity or composition of the outlet stream)- these are usually constrained by a plantwide optimization model; and (2) Minimizing costs through reduced fuel consumption and managing coking formation (fouling on the tube/process side of the furnace). Figure and Figure depict the major inputs used in operating an ethylene furnace and corresponding measurements. 


\section{Major Furnace Model Inputs}

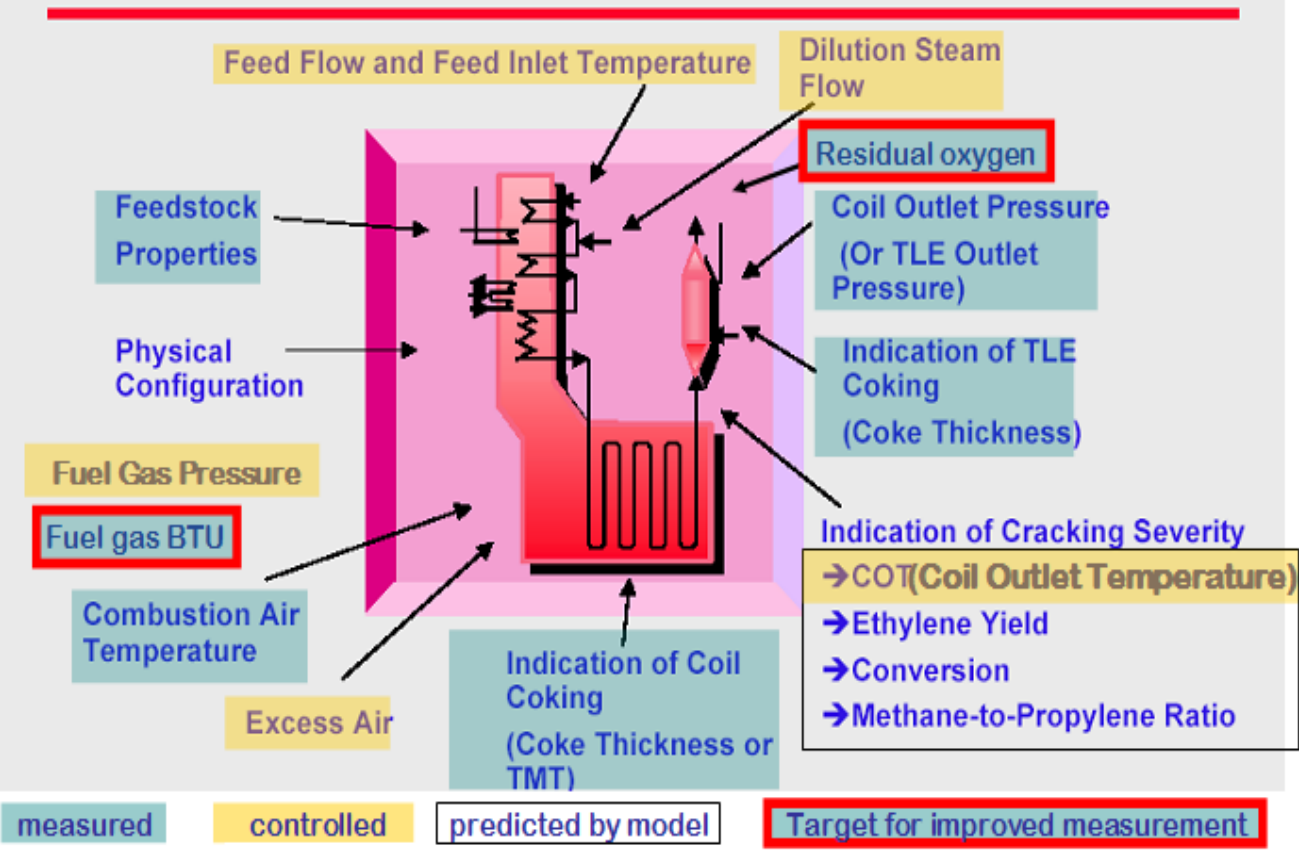

Figure 30. Schematic Olefin Furnace Major Model Inputs

\section{Cracking Furnace}

Integrated heat
recovery and
preheat

Hydrocarbon Steam Cracking

-SPYRO model of cracking - 20 years

-Run Strategy - Evolved over the past

decade based on R \& D Developments

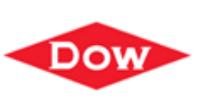


A complicated model based on reaction kinetics is used by the industry to optimize ethylene production and is 20+ years old (SPYRO). These same models are also used by most ethylene producers to optimize the furnace operation. A typical cracker has 5 to 7 large furnaces producing about one billion $\mathrm{lb} /$ year per cracker. There are several constraints in operating a furnace in olefins production including coke deposition which grows throughout the 1 to 2 month long run of the furnace- the constraint is the tube metal temperature. Current methodologies treat all tubes in the furnace as having the same thermal environment but in fact, it is known this assumption is not followed in most furnaces.

Referring to Figure for more detail, a single row of tubes is at the heart of the furnace- two rows of burners surround the tube on each side, at two levels to attempt to create a uniform radiative environment- typically 40 feet tall. In this configuration (typical of most furnaces), the constraints are:

- Control cracking -yield \& throughput $\$ \$$

- Uniform Tube Metal Temperature- run length (measured off-line, large uncertainty)

- Controlled Air to fuel ratio- uniform temp and mixing

- Control $\mathrm{NO}_{\mathrm{x}}$ and $\mathrm{CO}$ emissions- operational constraint

\section{Today's objectives and constraints}

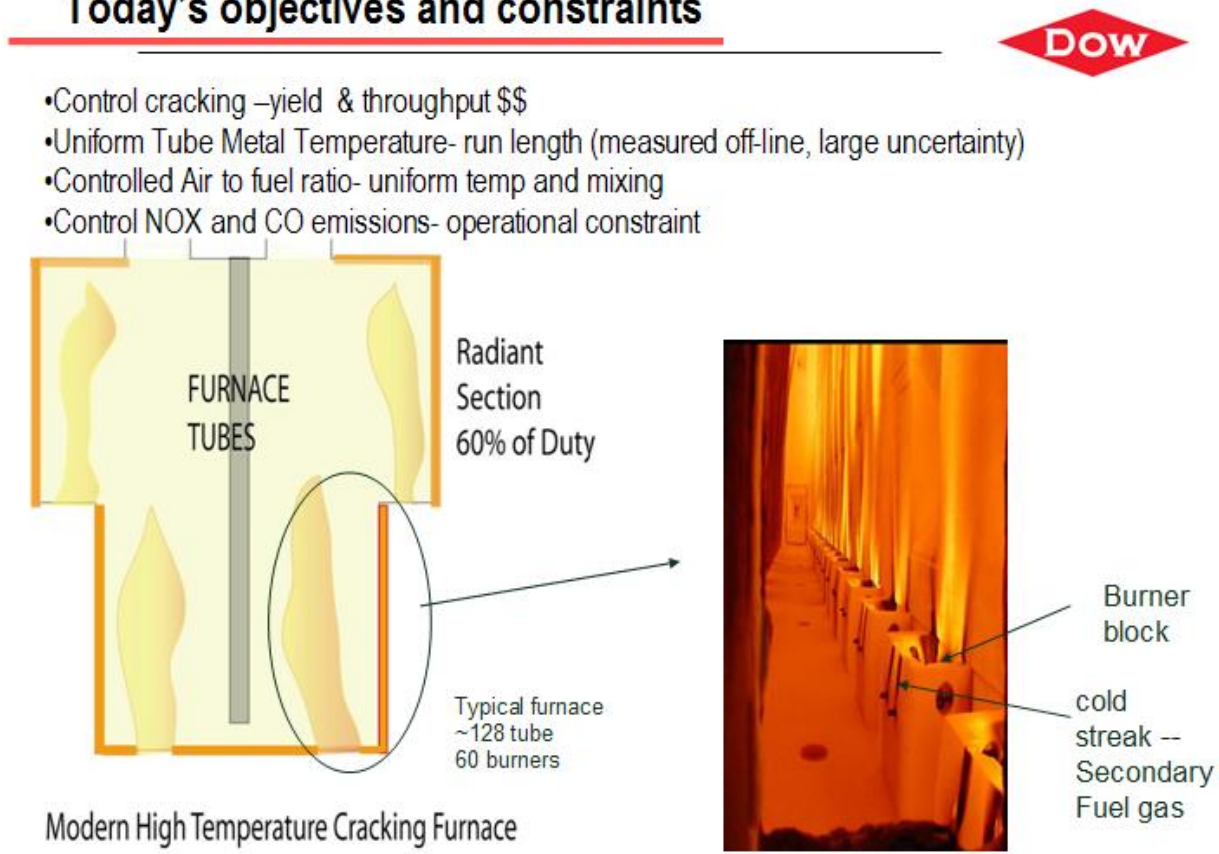

Figure 32. Typical Furnace Configuration and Operational Constraints

It is well-known that for most combustion processes the ability to optimize the air-to-fuel ratio is essential to maximize efficiency for fired-equipment. This situation is depicted in Figure below. For the case where the air-to-fuel ratio is "air rich", the process is in the "safe" condition where the potential for deflagration is reduced. However, operating too far above the ideal case results in poor efficiency and increased emissions (NOx, $\mathrm{CO}_{2}$, etc). In general, operating at $2 \%$ excess $\mathrm{O}_{2}$ corresponds to a $1 \%$ fuel cost. 


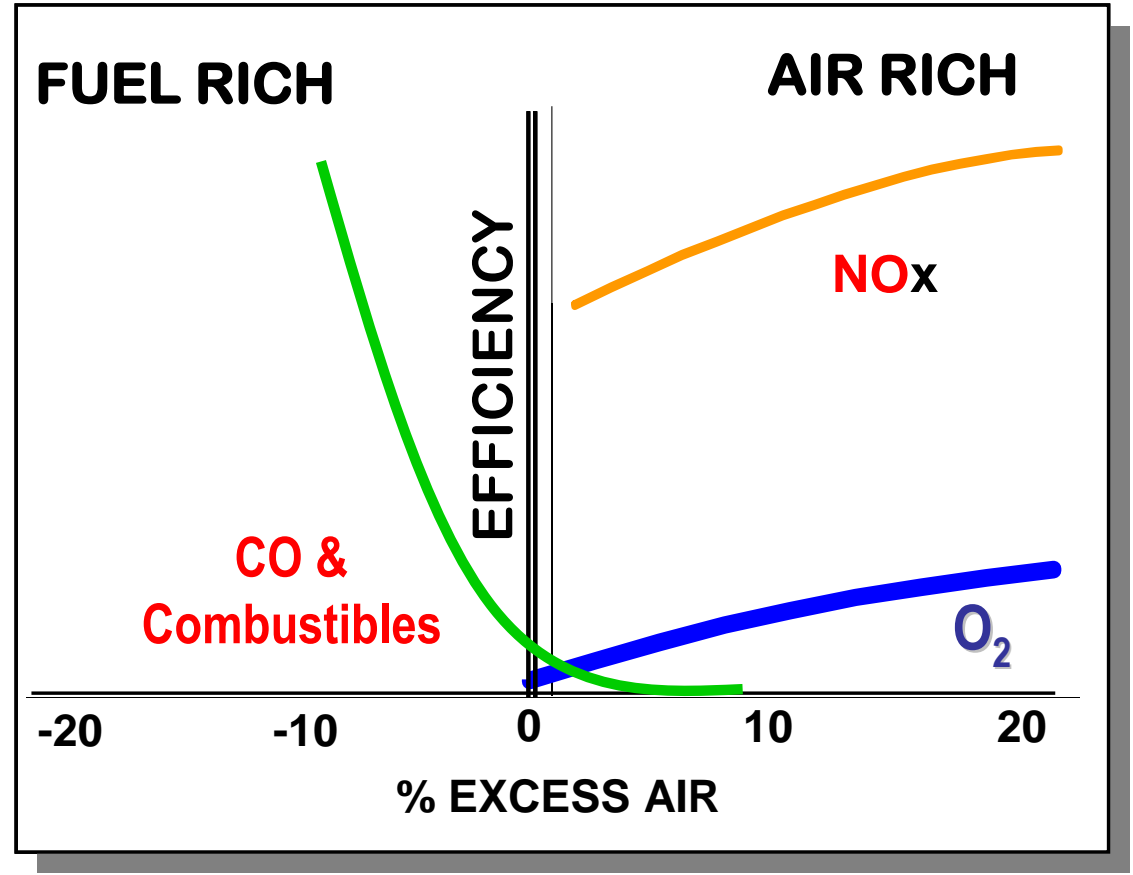

Figure 33. Combustion Process Optimal Efficienc. Optimal Efficiency for most combustion processes is near the stoichiometric ratio of air-to-fuel. The ideal condition is not steady-state and can change due to a number of variables including fuel-types, aging burners and equipment, measurement errors, etc.)

For the case where the air-to-fuel ratio is "fuel rich", the process is no longer in a safe condition as the potential for deflagration is much higher because of the increased levels of combustibles and $\mathrm{CO}$ in the fire box. This condition is not efficient either and in general, a level of $2500 \mathrm{ppm}$ of CO corresponds to a $1 \%$ fuel cost.

Ideally, the air-to-fuel ratio is set at its optimum condition independent of other variables typically encountered in industrial fired-equipment, such as fuel type, age of equipment, firing duty, etc. In order to optimize and control the air-to-fuel ratio, measurements of the operating constraints must be measured. One of the key constraints for most industrial combustion processes is $\mathrm{CO}$ breakthrough (the threshold at which lowering excess $\mathrm{O}_{2}$ results in a large, rapid increase in $\mathrm{CO}$ levels). The ability to reliably measure $\mathrm{CO}$ levels (and CO breakthrough in particular) is therefore critical to define the ideal setpoint for air-to-fuel ratio for any particular condition regardless of fuel type, firing duty, etc. Typically, this ideal condition is approximated (but not optimized) by operating the furnace at a pre-determined, fixed set-point for excess air that achieves safe levels of $\mathrm{CO}$ and combustibles, even if not optimal for efficiency.

Since the alarm threshold for $\mathrm{CO}$ stack emissions (measured separately at the stack exit by a continuous emissions monitor system, CEMS) for this furnace is fixed at $50 \mathrm{ppm}$, we constrained the lower $\mathrm{O}_{2}$ setpoint to $0.6 \% \mathrm{O}_{2}$ to avoid CO-breakthrough. This lower setpoint $(0.6 \%)$ was found to be the lower bound on this particular furnace based on data collected via TDL analyzers over a one-year period. This result is consistent with our experience, i.e., that $\mathrm{CO}$ continues to oxidize before it reaches the stack and that some negative deviations occur due to sample transport of the CEMS.

These data demonstrate that it is possible to continuously optimize the air-to-fuel ratio by manipulating the excess air setpoint, by relying on a real-time $\mathrm{CO}$ measurement in or near the combustion zone (via tunable diode laser), so-called CO trim control.

The other anticipated benefit from lowering the excess air via CO-trim is lowered NOx emissions. Figure 34 compares excess $\mathrm{O}_{2}$ measured via TDL in the arch of an ethylene furnace and NOx emissions measured at the stack exit via a continuous emissions monitor system (CEMS). We were able to 
demonstrate that indeed, reduced NOx emissions are realized by lowering excess air. This result is shown in Figure $\mathbf{3 4}$ and summarized in the corresponding embedded table. Upon lowering the excess air setpoint from $1.2 \% \mathrm{O}_{2}$ to $0.6 \%$ NOx emissions were significantly reduced ( $13 \%$ lower).

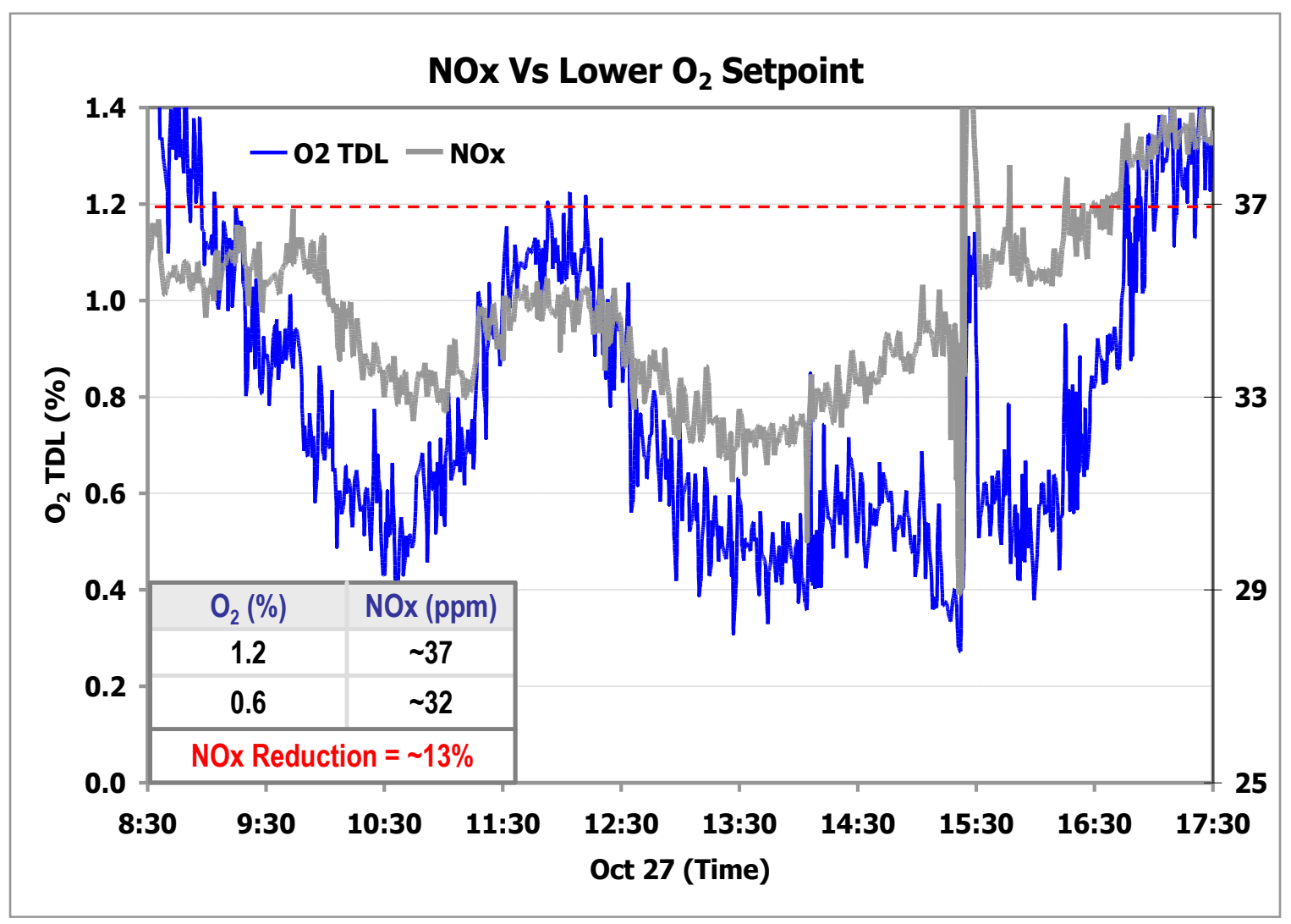

Figure 34. CEMS NOx Emission Level versus Lower Excess $\mathrm{O}_{2}$ Control Set Point

By applying the CO-trim concept described here and implementing the associated measurement technology in the approximately 200 olefins furnaces at Dow, we can roughly estimate the efficiency improvements:

- For an average olefins furnace in Dow- we estimate that we can save126,125 million BTU per year per furnace using this technology. Dow has roughly 200 similar furnaces.

We expect to leverage this technology on most of Dow's large inventory (approx 1,000) of large firedequipment - but their size and operating constraint are quite diverse. A detailed analysis would require a significant effort but are assuming we can achieve an additional $50-75 \%$ savings (olefins furnace basis). There is also an improvement in NOx reductions, but again, we have not examined this extensively. Our recent field trial revealed that there is about a 5\% improvement in NOx reduction (for a 250 million BTU/hr furnace). Similar savings should be achievable for all fired equipment where this technology is implemented- power generation, boilers, thermal treatment units (TTUs) etc.

Yokogawa (our commercial partner on this contract) estimates there are over 7,000 fired heaters in U.S. refineries and petrochemical plants. Their assessment divides the market into small fired heaters (100 MBTU/hr.) and medium (250 MBTU/hr.) sized fired heaters. Yokogawa is developing a commercial solution for fired heater combustion management based on the tunable diode laser spectroscopy (TDLS) technology developed in part through this DOE project, Their aim is to differentiate Yokogawa from its competitors by offering a self-contained solution that can improve safety margins, increase thermal efficiencies. 


\section{Publications:}

Conference presentations have been made based on the results of this project:

- "Laser-Based Analyzers For Improved Combustion Control", presented at International Forum for Process Analytical Chemistry (IFPAC), January 2007 Baltimore MD.

- "Ensuring Operational Excellence Through the Application of TDL (Tunable Diode Laser) Analyzer Technology" presented at Yokogawa's Users Conference in Barcelona Spain, September 2008.

- "Next Generation Solutions of Energy Management Through the Application of TDL (Tunable Diode Laser) Analyzer Technology" presented at ARC's 13th Annual Orlando Forum, February 2009, Orlando Florida.

- "Online Measurements for Improved Safety and Energy Management" presented at Plant Success Conference, Clear Lake Houston, April 162009.

\section{Networks or collaborations fostered:}

None

\section{Technologies/Techniques Developed:}

- Long-path CO/methane TDL analyzer (commercialized through Yokogawa)

- Method to improve optimization of olefins furnace via CO-trim control

Yokogawa is currently developing a "Combustion Solution" product offering centered around the TDL $\mathrm{O}_{2} / \mathrm{CO}$ technology. This Solution offering will consist of; TDL combustion gas analysis, additional furnace measurements (gas temperature, pressure, fuel feed pressure, flow, etc), control hardware, software and strategy, as well as individual furnace/process heater consultation and improvements. Initial information on this offering has been provided to the DOE, we expect this offering to be released in 2010. Currently we are performing the first installation on a process heater. More information on the product offering and commercialization route will be provided at a future date.

Dow has also started to implement the TDL measurements and optimization on ethylene furnaces and other fired heaters. The first commercial installations will be complete in 2010 and Dow has started the process of standardization (MET = Most Effective Technology) for ethylene furnaces and other fired equipment.

Inventions/Patent Applications and Licensing Agreements: None

For projects involving computer modeling, provide the following information with the final report:

Not applicable 